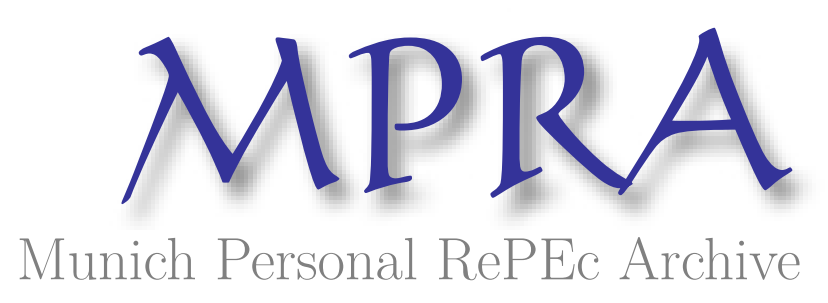

\title{
An Empirical Analysis of the Effects of GP Competition
}

Pike, Chris

Co-operation Competition Panel

1 August 2010

Online at https://mpra.ub.uni-muenchen.de/27613/

MPRA Paper No. 27613, posted 23 Dec 2010 22:13 UTC 


\title{
An Empirical Analysis of the Effects of GP Competition ${ }^{1}$
}

\author{
Dr. Chris Pike ${ }^{2}$ \\ Co-operation and Competition Panel
}

August 2010

\begin{abstract}
We analyse the relationship between the quality of a GP practice in England and the degree of competition that it faces (as indicated by the number of nearby rival GP practices). We find that those GP practices that are located close to other rival GP practices provide a higher quality of care than that provided by GP practices that lack competitors. This higher level of quality is observed firstly in an indicator of clinical quality (referrals to secondary care for conditions that are treatable within primary care), and secondly in an indicator of patient observed quality (patient satisfaction scores obtained from the national GP patient survey). The association between increased competition and higher quality is found for GP practices located within 500 metres of each other. However it would appear that the magnitude and geographic scope of the relationship are constrained by restrictions upon patient choice. As a result the findings presented here may only reflect a fraction of the potential benefits to patients from increased choice and competition.
\end{abstract}

Keywords: General Practice; Primary care; Competition; Quality

JEL Classifications: L11; L15; L84; L32; I11

\footnotetext{
${ }^{1}$ Thanks to Dr. Walter Beckert, Prof. Bruce Lyons, Dr. Tom Crossley, Prof. Hugh Gravelle, Prof. Peter Smith, Kate Collyer, Dr. Mette Christensson, Alistair Brown, Andrew Taylor, Nick Warren and Tim Burnett for valuable detailed comments. The paper has benefitted from being presented at the $1^{\text {st }}$ Co-operation and Competition Panel Economics Reference Group Seminar and the $10^{\text {th }}$ Centre for Competition and Regulatory Policy Workshop.

${ }^{2}$ Co-operation and Competition Panel, 1 Horse Guards Road, London www.ccpanel.org.uk/reports-and-guidance. e-mail: chris.pike@ccpanel.gsi.gov.uk or chris.pike.wh@gmail.com
} 


\section{INTRODUCTION}

The role of choice and competition in primary care in England has been a subject of some debate over the last decade. However, the debate thus far has been conducted without empirical analysis of the effects of competition in primary care. In the absence of empirical evidence, much of the public discussion has necessarily been restricted to the theoretical merits of choice and competition ${ }^{3}$ and anecdotal reports of its impact. ${ }^{4}$

This paper addresses the empirical gaps in our knowledge by analysing the effect that choice and competition has on the quality of primary care in England. The paper has two parts. In part 1, we describe the role of primary care as well as the scope for, and restrictions upon, competition in primary care. We also consider the impact of competition in primary care on competition in secondary acute care. In part 2, we present the results of an empirical analysis of the relationship between the quality of a GP practice and the degree of competition that the GP faces (as indicated by the number of nearby rival GP practices).

Our key finding in the empirical analysis is that those GP practices that are located close to rival GP practices provide a higher quality of care than that provided by GP practices that lack nearby competitors. This higher quality is observed from two different measures:

a) clinical quality (referrals to secondary care for conditions that are treatable within primary care); and

b) patient observed quality (patient satisfaction scores obtained from the national GP patient survey).

The association between increased competition and higher quality is found for GP practices located within 500 metres of each other. Both the magnitude and the geographic scope of the relationship appear to be constrained by the existence of both formal and informal restrictions upon patient choice. As a result the findings presented here may only reflect a fraction of the potential benefits to patients from increased choice and competition.

\section{PART ONE: Discussion and Context}

\section{The role of primary care in the UK}

In England general practice is, for the vast majority of people, the first and most commonly used point of access to the NHS. GPs in England are responsible for providing a range of services, including: more than 300 million consultations each year, (which amount to 90 percent of all contacts between patients and the NHS); prescriptions worth approximately $f 8.2$ billion each year;

\footnotetext{
${ }^{3}$ A good example of which is Paul Corrigan's paper "Registering choice: how primary care should change to meet patient needs" for the Social Market Foundation, 2005.

${ }^{4}$ See for example the policy paper “Choice and competition in primary care: much ado about nothing?" Ellins, J, Ham, C, and, Parker, H. November 2008.
}

UNCLASSIFIED 
minor treatments; referrals for specialist care; screening and immunisation; management of long term conditions; and public health promotion. ${ }^{5}$

Figure 1. Leaflet asking patients to choose their family doctor, 1948

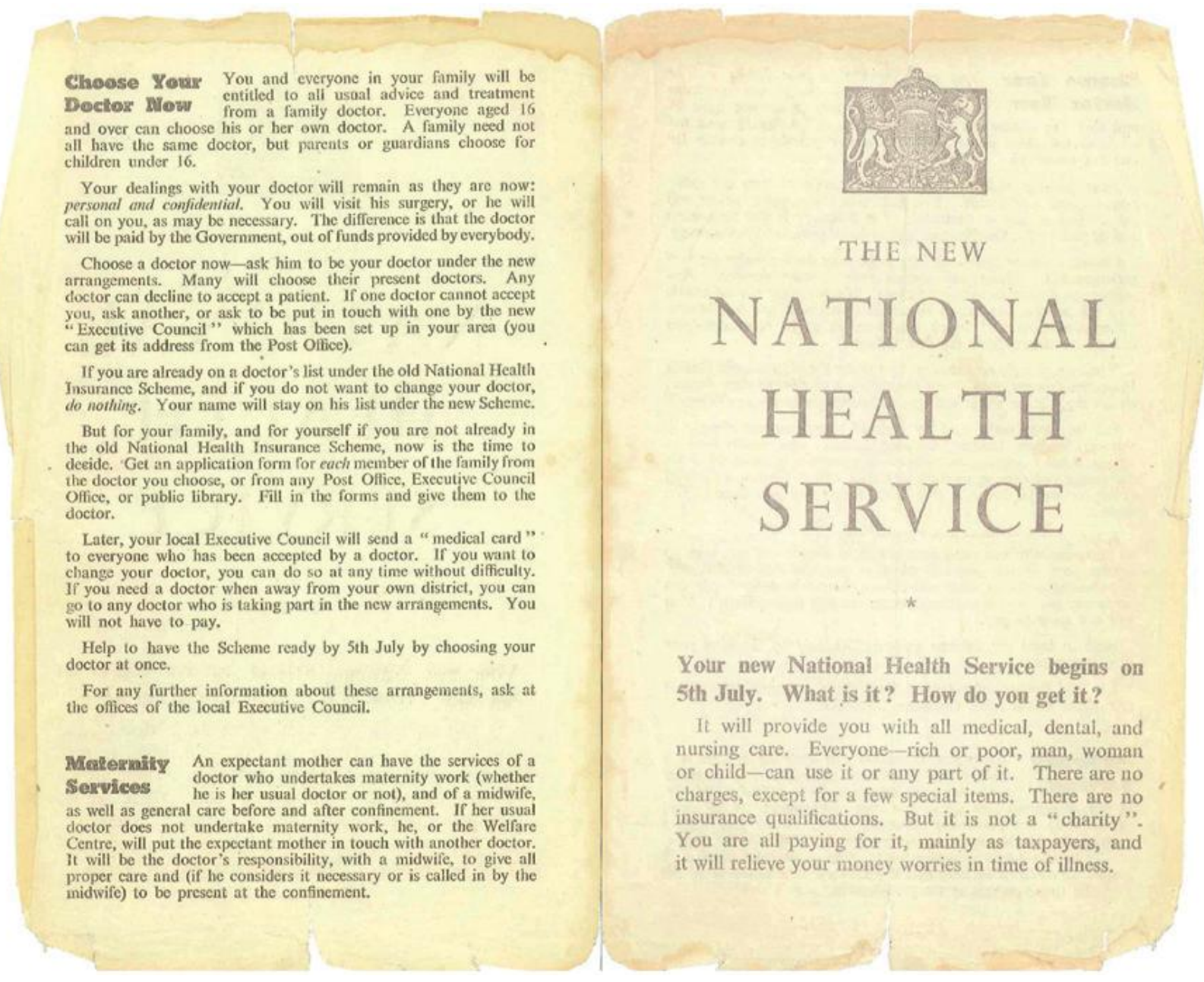

Since the creation of the NHS, more than 60 years ago, independently contracted GPs have provided the vast majority of all GP primary care services in England. As a result, there are currently more than 27,000 GPs who are partners in the independent GP practices across England from which the NHS purchases primary care services. These businesses are paid approximately $£ 7.9$ billion $^{6}$ each year to provide primary care to each and every person in England who chooses to register to receive

\footnotetext{
${ }^{5}$ Kings Fund Briefing September 2009

${ }^{6}$ "NHS Employers' evidence to the Pay Review Body on Doctors' and Dentists' remuneration 2009/2010- General Medical Services" November 2008, p7.

http://www.nhsemployers.org/Aboutus/Publications/Documents/NHS\%20Employers\%20evidence\%20to\%20the\%20Pay\%20Review\%20Bo dy\%20on\%20Doctors\%20and\%20Dentists\%20remuneration\%202009-10\%20-\%20General\%20Medical\%20Services.pdf.
}

\section{UNCLASSIFIED}


this service for free at the point of use. More than 10,000 salaried GPs are employed by these businesses to assist in the provision of this service. ${ }^{7}$

Each GP practice holds a list of registered patients to whom they are contracted by their local PCT to provide primary care services. Payments by the NHS follow the patient: the more patients that are registered with the practice the larger the fee that the GP charges to the NHS. ${ }^{8}$ Practices are free to register patients regardless of where they live. However, the practice may, at present, choose to refuse to register patients that live outside their agreed geographical catchment area. ${ }^{9}$ In addition to providing primary care services, GPs also act as a gatekeeper to secondary care through their responsibility for deciding when a referral for secondary care is required. Where this is the case they can offer the patient advice on which acute provider offers the best quality treatment. ${ }^{10}$ Since patients generally lack the technical expertise to assess this for themselves they require reliable and impartial guidance from their GP in addition to the information that they acquire from local or central government and media sources.

The quality of primary healthcare is crucial in driving improvements in the quality of outcomes that patients experience as well as the value for money that the taxpayer receives. Research has shown that in the UK in the 1990s one extra GP per 10,000 patients was associated with: a $6 \%$ reduction in mortality rate; a $14 \%$ reduction in hospital admissions for acute illnesses; and, an $11 \%$ reduction in hospital admissions for chronic illnesses. ${ }^{11}$ In this context, government policy over the last decade has had the effect of significantly increasing the quantity of GPs (the GP workforce grew by approximately 7,000 between 2000 and $\left.2008^{12}\right) \cdot{ }^{13}$

In the remaining first half of this paper we identify the scope for competition in GP services, restrictions upon competition that exist in GP services and the effect of GP competition on competition between acute hospitals. Finally, we discuss the potential for market failure in primary care.

\section{The scope for competition in GP services}

In considering the scope for competition in GP services we start by with the simple observation that patients choose their GP. They have to do so without advice but with the reassurance that

\footnotetext{
${ }^{7}$ These GP practices also employ administrative staff and nurses who provide approximately 38 percent of the 300 million consultations: http://www.guardian.co.uk/society/2010/mar/23/gps-consultations-ill-patients

${ }^{8}$ See paragraph [45] for additional detail on payments to GP practices

${ }^{9}$ Catchment boundaries are agreed between the GP practice and the PCT. The Department of Health is currently consulting on proposals to remove catchment areas. See paragraph 1.17 in Department of Health "Your choice of GP practice: A consultation on how to enable people to register with the GP practice of their choice" March 2010: http://www.gpchoice.dh.gov.uk/wp-content/themes/gpboundaries/documents/Your-Choice-of-GP.pdf

${ }^{10}$ Some GPs refer more than $90 \%$ of their patients to a single hospital. As such they may have little direct experience of alternative providers in the area. In contrast other GPs will have an opportunity to get feedback from patients attending a wide range of different hospital providers. These GPs will therefore be in a stronger position to provide up-to-date advice on the relative quality of treatment from different providers.

${ }^{11}$ See Gulliford M. "Availability of Primary Care Doctors and Population Health in England: is there an association?" Journal of Public Health Medicine 2002; 24: 252-4. More recently it has been shown that a 10 percent increase in primary care providers will increase the probability of reporting very good health by 6 percent (see "Are family physicians good for you? Endogenous doctor supply and individual health", Gravelle, Morris and Sutton, Health Services Review, August 2008, vol. 43, No.4, pp1128-44).

${ }^{12}$ Approximately 23 percent, see: http://www.ic.nhs.uk/statistics-and-data-collections/workforce/nhs-staff-numbers/nhs-staff-1998-2008-general-practice

${ }^{13}$ See: http://www.publications.doh.gov.uk/pdfs/nhsplanprimarycare.pdf
}

UNCLASSIFIED 
professional industry bodies will ensure that the providers maintain minimum professional standards. Patients have far from perfect information; however a (growing) selection of information is available with which to help them make a choice. For example patients use their own experiences, those of friends and family, and information provided by the government or the council (eg NHS Choices) on the level of convenience, access, facilities and service that are available from a particular provider to help them select their GP. ${ }^{14,15}$

While many attributes of the service provided by a GP practice can be adjusted relatively quickly, the location of the provider is fixed in the short term. ${ }^{16}$ For this reason GP practices provide services from their fixed location and have to compete by adjusting the different aspects of quality which they are able to control (eg opening hours, availability of appointments, access to the practice by phone or internet, service, facilities and the degree to which they involve patients in their decisions). ${ }^{17,18}$

We know that patients prefer conveniently located providers and so will base their choice of provider partly on the (relatively inflexible) location of the range of providers they are able to choose from. ${ }^{19}$ However, many patients do not make a choice based solely on the proximity of a GP practice and instead rely on an aspect of quality (eg opening hours, ability to get an appointment, service and facilities) that the provider is able to adjust. For example just $33 \%$ of patients in urban areas attend

\footnotetext{
${ }^{14}$ In table 1 of Salisbury (Salisbury C J. “How do people choose their doctor?" BMJ vol.299 $2^{\text {nd }}$ September 1989 p608) people choose GP largely on the basis of convenience (44\%) and some form of quality, (45\% eg recommended by others, used by other family members, has a female doctor, appears the best). See also Robertson, Dixon and Le Grand "patient choice in general practice: the implications of patient satisfaction surveys" Journal Health Service Res Policy vol13 No.2 April 2008)

${ }^{15}$ It is worth noting that many of these characteristics of GP services are shared with pharmacy services. Importantly none of these characteristics of the pharmacy market has prevented it from functioning as a regulated market. For more detail on the pharmacy market see the OFT report on pharmacies: http://www.oft.gov.uk/OFTwork/markets-work/completed/pharmacies

${ }^{16}$ In the medium to long term existing practices may decide to open branch practices. However whether they are allowed to do so is decided by the PCT. GPs may therefore be prevented from competing upon convenience of location.

${ }^{17}$ Notably in NHs funded GP services there is no price difference for patients to base their decision upon. This feature of the market removes the ability of providers to compete on price. As Gaynor (2004) suggests, fixed priced competition is expected to drive improvements in clinical quality. However, in markets with variable prices and imperfect quality information, competition may lead to a reduction in clinical quality (Chalkley and Malcomson, 1998, Gaynor, 2004, Kranton, 2003).

${ }^{18}$ The patient satisfaction survey measures how involved doctors and nurses make a patient feel in making a decision on their treatment. Research also shows that $75 \%$ of patients say that it is important to them that they can choose the hospital that treats them (King's Fund November 2009). However, at present just $48 \%$ of patients are actually offered choice by their GP (DH patient choice survey) and many of these choose not to be treated at their local provider (See http://www.kingsfund.org.uk/publications/patient choice.html). Patients may therefore prefer not to register with GP practices that do not meet their obligation to offer a choice of providers for elective treatment. For context choice of hospital is available through the "choose and book" system. Under the 2006/07 operating plan the proportion of referrals made via choose and book was intended to rise to $90 \%$, to this end a $f 100$ million incentive scheme was created to encourage GPs to offer patients choice via the choose and book system. However despite these payments just $54 \%$ of referrals are currently made via the system. There have been various complaints about problems caused by the system (eg http://www.guardian.co.uk/society/2010/mar/24/hospital-appointments-system-choose-book; and

http://www.bma.org.uk/ethics/health_records/connecting_for_health/chooseandbook.jsp). However, evidence submitted to the CCP suggests that this is no longer due to problems of functionality in the national choose and book system. Instead the poor utilization is a result of policies, processes and capacity issues (both for GP practices and acute Hospitals). One example is that GPs often complain that choose and book does not allow them to refer to a named consultant. This is not true. Choose and book does allow GPs to offer named consultant referrals but many Hospital Trusts have decided not to make this feature available.

${ }^{19}$ Kings Fund report: Choice at the point of referral, November 2009.
} 
their closest GP practice. ${ }^{20}$ On this basis it appears that there is scope for competition on the basis of 'quality' as well as convenience.

Where convenience remains an important aspect of choice, patients will choose between GP practices that are located close together (ie are geographically similar) ${ }^{21}$ rather than between more distant competitors. Furthermore where there are two closely matched GP practices (in terms of location and 'quality'), a patient is likely to consider the two practices as good substitutes for one another. As such a reduction in the 'quality' of one practice (eg by reducing opening hours) is likely to result in a patient choosing to register with the alternative practice.

The greater the number of patients that see two GP practices as substitutes, the greater the competitive threat that they will pose towards each other (ie the threat of patients choosing to register with the other GP practice). In this environment, GP practices located near to one another will each be under pressure to maintain or improve their 'quality' in order to retain or increase the number of patients that choose them (and thus create a profit for the owner of the practice).

However, observing the existence of the scope for competition is not the same thing as observing competition itself or its impact upon patients. We know that at present approximately 3.5 million patients (6.5 percent of a typical patient list) will switch to a different GP each year. ${ }^{22}$ To put this in the context of a non health sector, approximately 4-6 percent of bank customers switch banks each year. ${ }^{23}$ This suggests that there may already be a degree of competition between GP practices for new patients.

\section{Restrictions on competition in primary care}

If the scope for competition between GPs exists, then there is a question of whether that scope is being restricted. In this section we describe various restrictions on GP competition that are likely to be reducing the benefits of competition to patients and taxpayers. Given the empirical evidence of the benefits of competition identified in part 2 below, these restrictions evidently do not offset entirely the benefits of competition, although it seems likely that they prevent patients and taxpayers enjoying the full potential of these benefits.

\footnotetext{
${ }^{20}$ See Dixon, Gravelle, Carr-Hill and Posnett "Patient movements and patient choice" 1997. This suggests that patients were less likely to switch away from: bigger practices; those with more GPs; those that run more clinics; and those that open for longer hours. See also Deloitte's report to NHS Employers: Adjusting the General Medical Services Allocation Formula for the unavoidable effects of geographicdispersed populations on practice sizes and locations, March 2006. Billinghurst and Whitfield (1993) ran a survey to understand why patients who did not move house changed their GP practice. This showed that $12 \%$ of the patients that switched GP practices did not move house and of these, $37 \%$ of the patients moved to a GP that they believed would provide a better service and $36 \%$ changed on the basis of a recommendation or reputation of the GP.

${ }^{21}$ See Hotelling, H. 1929. "Stability in Competition" Economic Journal 39: p41-57; Salop, S. 1979. “Monopolistic Competition with Outside Goods" Bell Journal of Economics 10: p141-156.

${ }^{22}$ Source: NHS Connecting for Health (http://www.connectingforhealth.nhs.uk/newsroom/statistics/digest/010709.pdf). It is common to think of competition functioning when patients choose (or threaten) to switch away from a provider that they are dissatisfied with. However, in common with many other markets where location is of great importance the choice of provider will often be prompted by moving house.

${ }^{23}$ See OFT report on personal current accounts in UK banking sector: http://www.oft.gov.uk/OFTwork/marketswork/completed/personal/. For comparison with other sectors see also table 1 in Waddams and Chang "Gain or pain: does consumer activity reflect utility maximisation?" http://www.uea.ac.uk/polopoly fs/1.104668!ccp08-15.pdf
}

\section{UNCLASSIFIED}




\section{Barriers to entry and expansion}

Local Primary Care Trusts (PCTs) commission GP services for their population. ${ }^{24}$ It can select both the location of new practices and the characteristics of the provider (by specifying selection criteria for a tender and selecting the winner of that tender). This gives PCTs a powerful position as a planner of entry into the local primary care market. However, PCTs have not taken an active approach in this role and instead have tended to confine their activity to a) replacing existing practices when a GP retires, and b) implementing central government directed expansions in capacity (for example the 152 GP led health centres and 100 additional GP practices in under-doctored areas that were funded as a result of the Darzi report $\left.{ }^{25}\right)$. This is reflected in our estimate that approximately 116 new GP practices have been opened in the 152 PCTs in England between 2004/05 and 2008/09. ${ }^{26}$ Furthermore, the PCT also regulates the expansion of existing providers. In particular, a GP practice requires permission from its $\mathrm{PCT}$ in order to provide NHS services from a new branch practice. ${ }^{27}$

The limited amount of new entry in recent years means that GP practices remain distributed largely along historic lines. The entry that has occurred in this period has been directed by PCTs to those locations which have been underserved. While this has no doubt addressed an important policy objective, it has also meant that there is little scope for entry in response to any perceived opportunity (for example where an unchallenged incumbent practice is offering a poor level of service to its registered patients). Furthermore if there is an absence of spare capacity as a result of PCT imposed restrictions on entry then patients will be unable to switch practice. This may therefore seriously undermine the effectiveness of competition.

\section{Catchment areas}

An important restriction on patients' ability to choose their preferred GP is the catchment area that each GP practice agrees with its $\mathrm{PCT} .{ }^{28}$ This catchment area defines where patients must live in order to be sure of the chance to register with the GP in question. Patients living outside the area may request to register with the GP but can be rejected. Therefore, the catchment area has the effect of rationing the limited capacity that a GP practice has. However, in doing so it restricts competition between GP practices by limiting each patient's choice to those GP practices with a catchment area covering their home. This restriction limits the opportunity for patients to switch, or threaten to switch, to other GP practices.

In practice, catchment areas generally overlap to a degree and hence most patients can choose between at least two GP practices. Nevertheless, a significant number of patients are prevented

\footnotetext{
${ }^{24}$ However this function is due to shift to the independent NHS Board in April 2012, see: http://www.dh.gov.uk/en/MediaCentre/Pressreleases/DH_117360

${ }^{25}$ See http://www.dh.gov.uk/en/Publicationsandstatistics/Publications/PublicationsPolicyAndGuidance/DH_079077

${ }^{26}$ This estimate is based on a comparison the GP practices present in the 2004/05 information centre dataset and those present in the 2008/09 dataset.

${ }^{27}$ See http://www.ccpanel.org.uk/cases/Churchill-Medical-Centre-and-Kingston-Primary-Care-Trust.html. Where capacity is constrained a GP practice may be forced to declare its list to be closed. Similarly in some cases a practice may not officially declare its list to be closed though in practice this proves to be the case. In either situation the lack of capacity removes the incentive for that practice to compete for additional patients.

${ }^{28}$ However the use of practice boundaries is due to be abolished from April 2012 onwards, see http://www.dh.gov.uk/en/MediaCentre/Pressreleases/DH 117360
}

\section{UNCLASSIFIED}


from choosing the GP practice they would like to register with. For instance, the GP choice online survey ${ }^{29}$ found that $6 \%$ of people wanted to register with a GP practice near their place of work and $18 \%$ said they would be likely to register with a different practice in their local area if they were able to. The same survey showed that $20 \%$ of patients had considered switching GP practice without moving house (including $16 \%$ of those aged 55 or above). ${ }^{30}$

Research suggests that, on average, catchment areas cover approximately 2 square miles, though they vary significantly in size (between 0.19 and 13 square miles). ${ }^{31}$ Jenkins (1996) finds that in one London borough poorer quality GP practices have catchment areas three times larger than higher quality GP practices.

These catchment areas necessarily restrict patients' choice of GP and in doing so discourage patients from switching, or threatening to switch, GP practice. The effect of these catchment areas is therefore to restrict patient choice and competition, which reduces the need for practices to provide higher quality to attract patients.

\section{Fixed Payments to GPs}

There are a number of fixed payments to GP practices that do not depend on the number of patients registered at the practice. These payments reduce the incentives for GPs to compete to attract and retain patients. Examples of such payments include seniority payments and the minimum practice income guarantee (MPIG) which collectively cost $£ 405$ million each year. ${ }^{32}$ In addition, some PCTs offer ad hoc guaranteed fixed payments to certain GP practices. ${ }^{33}$

\section{Consolidation in local primary care markets}

Historically primary care has been provided by a fragmented group of independent providers, generally organised in small partnerships. There are, however, signs of increasing consolidation amongst providers. To the extent that such consolidation takes place within local primary care markets this may create a further restriction upon competition since GP practices within the same chain of practices are unlikely to have an incentive to compete with one another.

\section{The potential for collusion}

In every market it is important to be aware of the role of industry bodies. These bodies do a great deal of important work on behalf of their members. However, there is also a long history of cases in

\footnotetext{
${ }^{29}$ Ipsos-Mori, November 2009 (cited in Department of Health "Your choice of GP practice: A consultation on how to enable people to register with the GP practice of their choice" Department of Health consultation March 2010)

${ }^{30}$ The survey also suggests that: a) disabled patients can be up to $6 \%$ less satisfied with their GP practice than those of the same age without a disability; b) that satisfaction with GP services amongst some South East Asian communities is up to $15 \%$ than for white British people. Other research quoted in the Department of Health's consultation on GP practice boundaries reports that $17 \%$ of transgender people reported that they were refused standard healthcare treatment by a doctor or nurse because they did not approve of gender reassignment. The ability to switch provider is particularly important for those that are not satisfied or are refused care by their existing provider.

${ }^{31}$ Jenkins, C and Campbell, J: "Catchment areas in general practice and their relation to size and quality of practice and deprivation: a descriptive study in a London borough" British Medical Journal 1996 volume 313, pp1189-1192

${ }^{32}$ Featherstone, $\mathrm{H}$ and Storey, C: "Which Doctor?" Policy Exchange. January 2010. See also http://www.pulsetoday.co.uk/story.asp?storycode=4123917

${ }^{33}$ See http://www.ccpanel.org.uk/cases/Churchill-Medical-Centre-and-Kingston-Primary-Care-Trust.html
}

\section{UNCLASSIFIED}


which these bodies have been co-opted as a forum in which to collude and eliminate competition between the members. ${ }^{34}$ In primary care markets there are a number of important local provider bodies including Local Medical Committees, local GP federations, and practice based commissioning clusters (or GP commissioning consortia as they are to become). Each of these has comprehensive coverage of the GP practices within their local area and hence provides an opportunity to facilitate anticompetitive agreements between members.

Anti-competitive agreements between members might take the form of market sharing agreements or "no-poaching" policies that discourage advertising to other members' patients or registering patients from other practices. Where collusion between GP practices occurs it will reduce the level of competition and thereby reduce the beneficial impact of competition. To the extent that such collusive agreements are in place it will mean that the potential beneficial effect of competition that we have identified is an underestimate.

\section{Conclusion}

Given these formal and informal restrictions on choice and competition, some of which are well documented, others of which are possibilities, it is unsurprising that in January 2006 the Department of Health declared that "choice of practice in primary care is too often more of a theoretical proposition than a practical reality". ${ }^{35}$ We would therefore expect that these restrictions will constrain both the magnitude and the geographic scope of competition. As a result the findings presented here may only reflect a fraction of the potential benefits to patients from increased choice and competition.

\section{The broader effects of GP competition}

This paper is focused upon the role that competition between GPs has in local primary care markets. However, it should also be recognised that a competitive GP market can have an important beneficial effect on competition in the follow-on market for acute treatment. In this section we discuss this additional effect of GP competition.

In England providers of acute elective care (generally hospitals and treatment centres) compete to attract patients who require elective treatment. The providers are paid a fixed price for the specific treatment that they provide to each patient (this is defined within the national tariff as set by the Department of Health). Elective patients are able to choose to be treated at any hospital in the

\footnotetext{
${ }^{34}$ For example: Tractors (UK); Industrial bags (Belgium, Germany, Spain, France, Luxembourg and the the Netherlands); Petrol, Fertilisers, Steel (all South Africa), Cement (South Africa); citric acid (US); retail travel agents (US); professional engineers (in which the US Department of Justice challenged a professional society's prohibition in its canon of ethics of competitive bidding by its members (National Society of Professional Engineers v. U.S.). In that case the Supreme Court held that the trial court was justified in refusing to consider the defence that the canon was justified because it was adopted by members of a learned profession for the purpose of minimizing the risk that competition would produce inferior engineering work endangering the public safety. See "Potential Pro-Competitive and Anticompetitive aspects of trade/business associations" October 2007, US submission to the OECD Working Party No. 3 on Co-operation and Enforcement)

${ }^{35}$ Department of Health "Our health our care our say: a new direction for community services", January 2006, paragraph 3.18. It should be noted, however, that subsequently, between 2006 and 2009, the number of GPs in England has increased by 4,000 to 40,269 (an increase of 9,000 since 2000) though this increase has not been reflected in an increase in GP practices (see paragraph [18]). See http://www.ic.nhs.uk/statistics-and-data-collections/workforce/nhs-staff-numbers/nhs-staff-1999--2009-general-practice
}

\section{UNCLASSIFIED}


country that is on the NHS 'Choose and Book' system. Patients receive care free at the point of use and are therefore free to choose on the basis of convenience and quality.

We know that 36 percent of patients that choose their acute provider ask their GP's advice when making a choice of acute care provider. The GP is therefore likely to play a key role in deciding which acute provider treats many of these patients (in addition to the other 51 percent of elective patients did not recall being offered a choice by their GP). Given the importance of the GP in these patients' decision making process, acute providers will have an incentive to compete for referrals from GPs (particular since they choose repeatedly). ${ }^{36}$ That they do so is evidenced both in the recent Kings Fund research, ${ }^{37}$ and the tools provided to hospitals by Dr. Foster Intelligence which are designed to help the hospital to identify GP practices in which they are gaining or losing market share. This allows the hospital to target its efforts to retain or expand its patient volumes.

GPs have a professional interest in helping patients. However competition between GPs provides an additional incentive for them to offer a better quality service to patients. If GPs do not compete with one another in their local primary care market to register patients then there is no material incentive for GPs to switch, or threaten to switch, their referral between acute providers on the basis of the quality of treatment offered. This is because in the absence of GP competition the GP will not be adversely financially affected if a patient that they refer for further treatment subsequently experiences poor acute treatment (ie even if the patient holds the GP responsible the patient will not switch to a rival GP or tell others of their experience and so there is no risk that the GP will lose any income as a result of the poor treatment).

In order for hospital competition to function in the absence of competition between GP practices (and well informed patients) it would be necessary that every GP become a pro-active agent of the patient who seeks out the best acute care for each individual patient despite having no financial motive or any additional resource with which to do so. ${ }^{38}$ Unfortunately the lack of such an approach is evident in the way that many GPs refer to the local hospital regardless of the quality of treatment that it provides. ${ }^{39}$

As a result competition within primary care markets can force GPs to consider the quality of care that their patients receive in the hospitals to which they refer. This consideration can be seen as playing an important role in improving outcomes for patients in acute care if it strengthens the incentives for hospitals to compete with another to attract GP referrals (in addition to attracting

\footnotetext{
${ }^{36}$ Having said this, many patients do not rely solely on their GP's advice and instead consider their own experiences alongside those of their friends and family, and so acute providers will have an incentive to compete for these individual patients (rather than competing for the bundle of referrals that a GP makes). For example hospital websites and decisions made by hospitals (eg locating outpatient clinics in convenient community settings) suggest that hospital providers do seek to appeal directly to patients.

${ }^{37}$ See http://www.kingsfund.org.uk/publications/patient choice.html).

${ }^{38}$ Guidance from the General Medical Council requires GPs to act in the best interests of their patient (see Good Medical Practice, paragraph 74). However this obligation does not appear to require the GP to refer their patient to the best hospital in England (to do so might in fact conflict with patient choice where a local provider is favoured by the patient). Thus the obligation appears to require the GP simply to refer to a hospital when the patient requires hospitalisation, not to the "best" hospital, which is itself an ill-defined concept (given the many varied measures of quality) that is likely to conflict with the patient's other priorities.

${ }^{39}$ See http://news.bbc.co.uk/1/hi/health/947204.stm and http://news.bbc.co.uk/1/hi/england/staffordshire/7948293.stm
}

\section{UNCLASSIFIED}


individual patient choices). This is likely to be reflected in the results of a number of pieces of emerging research that identify the benefits of competition in hospital markets. ${ }^{40}$

\section{Market Failure}

While there is scope for competition between GPs, albeit somewhat restricted by a number of features (discussed above), there is also the potential for market failure. We next briefly address a number of concerns regarding potential causes of market failure in primary care.

\section{Asymmetric information}

The key market failure risk in every healthcare system is that posed by asymmetric information. Patients' often lack information and so, in contrast to well-informed clinicians, may not be able to compare alternatives and make optimal purchasing decisions. The solution adopted in the English NHS is three-fold.

a) the patient contracts with an agent (by registering with a GP). This GP agent is an independent source of expertise and information and is in a position to help the patient to obtain appropriate treatment for any given health requirement. This agent can resolve the asymmetry by increasing the knowledge and information upon which a patient can rely.

b) the Care Quality Commission (CQC) and the General Medical Council regulate and license provider organisations and individual doctors in order to ensure that a basic level of competence is available from any certified doctor or provider. While this does not directly address the asymmetry it is designed to prevent unqualified or unsafe doctors and providers from abusing the asymmetry that does exist.

c) the Department of Health provides a range of quality indicators and reports which are intended to signal differences in quality provided by different providers. Publicity of these indicators can be considerable and can therefore impact upon the reputation of a hospital or a GP practice.

Each of these solutions is not without cost. The quality assurance process incurs a cost as does the provision of information and GP agents for patients to register with. However, the benefits in terms of the quality of treatment received by the uninformed patient are believed to outweigh these costs.

\section{Duplication of provision}

Competition requires the existence of alternative providers for patients to register with, if their existing provider is unsatisfactory or if their circumstances change (eg move house or move job). The existence of multiple providers requires a degree of duplication in the services that are offered.

\footnotetext{
${ }^{40}$ This growing field of analysis of the post 2002 NHS reforms stands in marked contrast to the literature review produced by Civitas in March 2010 which reviewed the effects of competition in the internal market of the 1990s, but was not able to examine the effects of competition under the market reforms introduced in 2002. See for example: Cooper et al (2010); Gaynor et al (2010); and Bloom et al (2010)
}

UNCLASSIFIED 
Taken to the extreme such duplication can be excessive and therefore inefficient. ${ }^{41}$ For instance a GP surgery on every street corner would improve access for patients but the costs of setting up and maintaining such a network would be unsustainable. However, having no choice of alternative provider might mean the GP practice reduces its quality, for example it might close its branch practice, or reduce opening hours, or spend less time reading the latest medical research. If any of this happened the patients would then have nowhere else to go when they needed a GP. There is then a risk that an awareness of this lack of competition might in turn increase the risk of such deterioration in quality occurring.

Therefore, the number of alternative providers that exist and the amount of duplication that occurs is a question of degree. In England, PCTs currently have the responsibility of contracting with GP practices for the supply of primary healthcare. These PCTs pay a proportion of each GPs fixed costs and have a duty to ensure there is both sufficient diversity of providers and sufficient provision within each area. ${ }^{42}$ The PCT is therefore in a position to prevent excessive duplication of fixed $\operatorname{costs}^{43}$.

\section{Transaction costs}

For small procurements the costs of running a competitive tender may in some cases outweigh the benefits of having competition for those services. The European commission's public procurement regulation requires competitive tendering of only those contracts worth more than $£ 4,000^{44}$. However, where competition functions via patients choosing from any willing accredited provider (as it does in both GP and hospital competition) this issue would not arise.

\section{Gold plating}

One possible effect of competition between GPs is that some may respond to the demands of patients by increasingly offering home visits. In Belgium for example, intense competition between GPs is sometimes cited as a contributing factor behind the unusually high rates of home visits by GPs (46 percent) $)^{45}$. If such additional services were charged to the PCT this might be considered to represent a cost to the taxpayer that does not provide value for money ${ }^{46}$. As a result PCTs have to be clear about the limits on funding for such home visits. However, if GP practices choose to offer more of these at their own cost in order to attract patients, that would constitute a further beneficial effect of competition.

\footnotetext{
${ }^{41}$ See for example Mankiw and Whinston, Rand 1986. See also Salop, Bell journal of Economics 1979.

${ }^{42}$ The PCT will therefore need to balance twin objectives of achieving optimal capacity usage while at the same time creating sufficient capacity to allow for competition between GPs

${ }^{43}$ Though some use this position to protect incumbents from competition: http://www.ccpanel.org.uk/content/cases/Churchill-MedicalCentre-and-Kingston-Primary-Care-Trust/CCP-Report-on-Churchill-Medical-Centre-and-NHS-Kingston(18-12-09).pdf

${ }^{44}$ See http://www.out-law.com/page-5964.

${ }^{45}$ See: http://informahealthcare.com/doi/ref/10.3109/13814789909094245; and http://informahealthcare.com/doi/abs/10.3109/13814780109094331

${ }^{46}$ In England home visits are funded by the GP practice.
}

UNCLASSIFIED 


\section{Ensuring access to primary care}

Where patients are allowed the freedom to choose which GP practice to register with it is likely that GP practices providing poor services may lose patients. In doing so they may consider exiting the market. In such a case we would expect the practice to observe its slow decline and to address that decline by improving the service it provides to patients. Where it is unable to do so, stronger GP practices are likely to merge with the failing practice or to replace the failing practice by opening a new branch practice in the area in order to register the patients that live in the area. ${ }^{47}$

However, there may be cases when GPs in more isolated areas provide a good service but lack the number of patients to make provision of primary care in that area a profitable decision. ${ }^{48}$ This might happen because the population of the area has fallen, or because some of those living in the area have switched to GP practices near their work place ${ }^{49}$. In Scotland there are many instances in which practices are too small to be profitable, and yet provide important access for those patients that use the service. In those cases there is an adjustment formula which provides additional funding for GP practices serving patients in isolated $\operatorname{areas}^{50}$. This funding means that GP practices will voluntarily enter these markets and provide services despite the small numbers of patients.

In England, PCTs are responsible for providing sufficient choice of primary care provider for patients in their region. Where exit occurs for the types of reasons described above, it is incumbent upon the PCT to decide whether it is socially beneficial to have provision in that location ${ }^{51}$ and, if so, to competitively tender the provision of primary care services in that area. This will allow potential providers to bid according to the fee per patient that will make provision in that location profitable ${ }^{52}$.

\section{Summary}

There are a range of potential market failures within the primary care market; however solutions are already in place to ensure that these potential market failures do not occur.

\footnotetext{
${ }^{47}$ Though these would each require support from the local PCT.

${ }^{48}$ Similar issues may arise for example in relation to certain public transport links, postal services and broadband internet connection.

${ }^{49}$ Just $6 \%$ of patients said they wanted to switch to a GP practice near their work in the GP patient choice survey November 2009 . As such the issues we address in this section are likely to be extremely rare.

${ }^{50}$ See Deloitte's report to NHS employers: Adjusting the General Medical Services Allocation Formula for the unavoidable effects of geographic-dispersed populations on practice sizes and locations, March 2006.

${ }^{51}$ This will require the PCT to take a view on the benefits in terms of access for this set of patients as against the likelihood of greater costs of providing primary care services to this group from this location.

52 Quality will continue to be regulated by the relevant authorities to ensure a minimum standard is met. However by definition these are monopoly areas and so there is no prospect of the beneficial effects of competition being provided to these consumers.
}

\section{UNCLASSIFIED}




\section{PART TWO: The Empirical Analysis}

\section{Revenue sources for GPs}

GP practices are private firms generally owned by one or more partners. The partner GPs may employ salaried GPs in addition to the nursing and administrative staff that work at each practice ${ }^{53}$. The GP practice may be based at a single site or may provide its services from a number of sites (where this is the case we refer to additional sites as "branch practices"). GP Practices in England can earn income from the NHS via five payment mechanisms ${ }^{54}$;

a) A global sum payment (on average $52 \%$ of total revenue in $07 / 08$ ). This is based on the weighted needs of the practice's patient list. The global sum payment is based on a national allocation formula, calculated according to list size and adjusted for the age and needs of the local population. ${ }^{55}$

b) The practice's Quality Outcomes Framework (QOF) score (14\%)

c) Payments for providing an enhanced range of services (10\%)

d) PCT administered funds eg premises reimbursement, seniority payments to experienced GPs (14\%)

e) Payments for dispensing pharmacy products (10\%).

As privately operated organisations, we can expect the partners of the practice to act to increase each of these revenue streams where the cost of doing so does not outweigh the revenue that is to be gained. ${ }^{56}$ For example they will choose to provide enhanced services if they are able to provide such services at a cost less than the revenue that they receive from the PCT for providing those services.

\section{Quality setting by GPs}

From the payment mechanisms above, it can be seen that there are at least two ways in which the quality of care that is provided at a practice may affect the profits that the practice achieves.

\footnotetext{
${ }^{53}$ These GPs are paid by the practice and not by the PCT. Minimum terms and conditions for salaried GPs working in GMS (General Medical Services) practices were agreed between the general practitioners committee (GPC). However GMS practices are free to negotiate improved terms for salaried GPs without an upper limit. PMS (personal medical services) and APMS (alternative providers of medical services) practices are free to set their own terms and conditions.

${ }^{54}$ See Making Sense of Health and Care: the DH Policy Framework (Version 1, October 2008), page 164. This breaks down into two forms of contract. Approximately 60 percent of practices are contracted via the General Medical Services (GMS contract) which is nationally negotiated while the remaining practices are paid under locally negotiated Personal Medical Services Contracts (PMS). The payment under PMS is typically the amount that the practice would have received under a GMS contract with an additional payment to cover the cost of extra services which the PCT wants the practice to provide.

${ }^{55}$ When the new GP contract was introduced in 2004 it was also agreed to include a minimum practice income guarantee (MPIG) which ensured that income did not fall below a fixed level that the practice had received prior to the new GP contract.

${ }^{56}$ See for example Gravelle, Sutton and Ma: "Doctor behaviour under a pay for performance contract: treating, cheating and case finding?" Economic Journal, v120, February 2010, pp129-156. See also: Croxson, Propper and Perkins “Do doctors respond to financial incentives? UK family doctors and the GP fundholder scheme" Journal of Public Economics, vol 79, No.2, February 2001, pp375-389
}

\section{UNCLASSIFIED}


Firstly setting a high level of quality will help practices to retain existing patients and to attract additional new patients to register with the practice. This will increase the global sum payment that the practice receives.

Secondly, the practice earns more revenue if it scores more QOF points in its annual review. QOF points are a payment mechanism introduced as part of the new General Medical Services (GMS) contract on 1 April 2004. Up to 1000 QOF points can be awarded to a practice on the basis of clinical quality, organisational quality, patient satisfaction, and additional services. Each QOF point awarded is worth approximately $f 122$ in revenue each year ${ }^{57}$. By scoring more QOF points a practice is therefore able to increase its income.

QOF

We analyse variations in QOF scores in the appendix, however in our main analysis we focus upon two alternative measures of different aspects of the quality of a GP practice. This is because there are a number of aspects to the QOF scoring system that suggest that we should not expect QOF scores to be influenced by competition, none of which apply to the quality measures that we have chosen to examine:

The Department of Health warns that "a lower quality (QOF) achievement does not necessarily mean that patients are receiving poorer quality care" ${ }^{\prime 58}$. This is because "it is recognized that levels of QOF achievement will be related to a variety of local circumstances and should be interpreted in the context of these circumstances." For example the information centre notes that for some practices it may be impossible to achieve all of the points available in the QOF. ${ }^{59}$ Thus QOF may not be a good comparative measure of quality. Furthermore research suggests that QOF scores are subject to gaming by primary care providers, via the exception reporting aspect of the QOF points scoring system. ${ }^{60}$

QOF payments are not zero-sum; there is not a fixed budget that is allocated on the basis of QOF score. Instead improved scores can be achieved by each GP in an area at no cost to other GPs in the area. As a result we might not expect QOF scores to be driven by competition between practices. Instead they may reflect greater mutually beneficial cooperation between GPs (eg where best practice is usefully shared). If there is such a cooperative effect, and, despite the reservations in (i)

\footnotetext{
${ }^{57} 650$ QOF points are scored for clinical aspects of the service. 36 points are allocated for patient experience. Finally 167.5 points are scored for organisation and 147.5 point for additional services.

${ }^{58}$ http://www.dhsspsni.gov.uk/qof context

${ }^{59}$ For example, some clinical indicators relate to specific subgroups of patients, and if the practice does not have any such patients it cannot score points against the relevant indicators. In addition, practices with PMS contracts may include quality and outcomes as part of their locally negotiated agreements, and in may opt to use part or all of the new GMS QOF as a measurement tool, thus they may not aspire to score all of the QOF points that are available. For further details on QOF see: http://www.qof.ic.nhs.uk/faqs.asp

${ }^{60}$ This is set out in 'Doctor Behaviour under a Pay for Performance Contract: Treating, Cheating and Case Finding?' by Hugh Gravelle, Matt Sutton and Ada Ma February 2010, Economic Journal.
} 
QOF measures some aspects of quality, then the relationship between QOF scores and competition will be ambiguous. ${ }^{61}$

There is very little variation in QOF scores; $90 \%$ of GP practices receive a QOF score of $92 \%$ or more, and half the GP practices in England score more than 99\%. Thus, all else being equal, the best practice in the country receives just $£ 100$ more funding each month than the median practice. ${ }^{62} \mathrm{As}$ such the incentive to invest to improve the QOF score of the practice is not significant.

Quality

The first quality measure that we examine is an indicator of the clinical quality of each GP practice. This is the number of ACS (Ambulatory Care Sensitive) referrals to hospital that are made by each GP practice in England ${ }^{63}$. ACS conditions are a set of 19 conditions for which timely and effective primary care can help to prevent the need for hospitalisation. The conditions include;

a) Chronic conditions where effective care can prevent flare-ups (asthma, COPD, diabetes, congestive heart disease, etc);

b) Acute conditions where early intervention can prevent more serious progression (ENT infections, cellulitis, pneumonia, etc); and,

c) Preventable conditions where immunisation can prevent illness. ${ }^{64}$

We take the number of referrals that each GP practice made in 2008 for conditions included in the ACS basket. For example GP Practice X made 81 referrals to acute hospitals in 2008 for treatment of ACS conditions. As such the variable for ACS referrals made by GP Practice $X$ reads " 81 ". Higher numbers of referrals to secondary acute hospitals for these conditions are widely acknowledged amongst commissioners, think-tanks, policy makers and within clinical studies as reflecting a poorer quality of primary care at a given GP practice. ${ }^{6566}$

\footnotetext{
${ }^{61}$ Table 12 considers whether a practice's QOF score can be explained by the number of other GP practices in an area (these might be considered potential competitors or co-operators depending on the hypothesis adopted). Consistent with our expectation we find no relationship between QOF score and the number of other GP practices.

${ }^{62}$ By "all else being equal" we assume that the list size and the prevalence statistics for the practices are the same, hence only quality of service differs. The best GP practice scores $100 \%$, the median practice scores $99 \%$, thus $1 \%$ over 12 months is worth approximately $f 100$. ${ }^{63}$ These referrals can be identified in the Hospital Episode Statistics (HES) dataset that is collected by the Department of Health's Information Centre. As we explain in the model below we control for patient list size, disease burden and age profile of the local population. This standardises the number of ACS referrals that would be expected at a given GP practice.

${ }^{64}$ The full set of ACS conditions are as follows: angina; asthma ; cellulitis; chronic obstructive pulmonary disease (COPD); congestive heart failure; convulsions \& epilepsy; dehydration \& gastroenteritis; dental conditions; diabetes complications; ENT infections; gangrene; hypertension; Influenza and pneumonia; iron deficiency anaemia; nutrional deficiencies; other vaccine; pelvic inflammatory disease; perforated/bleeding ulcer; and, pyelonephritis

${ }^{65}$ See for example the research of the UK based Nuffield Trust (a Health think tank) on ACS conditions:

http://www.nuffieldtrust.org.uk/projects/index.aspx?id=918 There is also a wide variety of clinical research papers based on ACS conditions:http://www.ingentaconnect.com/search;jsessionid=1/ha1yc6m3owp.alice?database=1\&title=Ambulatory\%20care\%20sensitive $\% 20$ conditions. Commissioners use ACS conditions, see for example:

http://www.ealingpct.nhs.uk/Library/JSNA/JSNA_June_2008_Reference_Documents/Ambulatory_Care_Sensitive_Conditions_2007.doc and also: http://www.erpho.org.uk/Download/Public/19016/1/Comm\%20brief\%201\%20ACSC\%20FINAL\%20A4\%20+\%20live\%20links.pdf In light of commissioners using ACS conditions, firms such as Dr. Foster now sell tools to measure ACS referrals to PCT commissioners in order to help them manage their primary care contracts: http://www.drfosterintelligence.co.uk/managementinformation/HUM/. Finally for an example of ACS admission rates being used by policymakers to assess the standard of primary care, see the following example in New York: http://www.nyc.gov/html/hhc/downloads/pdf/pcdc-report.pdf
} 
Our hypothesis is that the presence of alternative rival GPs in the area will compel GPs to provide a high standard of care (which will then be reflected in a low ACS referral rate) in order to build a reputation that will attract and retain patients (and the income associated with those patients). ${ }^{67}$ The determinants of reputation may be many and varied, however we would expect that the quality of care will play some role. Indeed, research suggests that patient satisfaction may be correlated with reduced referrals to acute hospitals. ${ }^{68}$

The second measure reflects patient experience as reported by the most recent GP patient survey (2008). This was designed to reflect patients' assessment of the quality offered by each GP practice in England ${ }^{69}$. Patients were selected for the survey at random from GP registered patient lists. ${ }^{70}$ However participation by those that were selected randomly was completely voluntary. Ipsos MORI, who conducted the survey on behalf of the Department of Health, received a total of 1,999,523 valid responses from a total sample of 5 million people, a response rate of 41 per cent overall. ${ }^{71}$

We use the patients' response to the multiple choice question: "overall satisfaction with care received at the practice: very satisfied; fairly satisfied; neither satisfied nor dissatisfied; fairly dissatisfied; or, very dissatisfied". We take the percentage of patients that were satisfied (very or fairly) as the score for each practice. For example $91 \%$ of respondents who were registered at GP Practice $X$ were very or fairly satisfied overall with the care they received at the practice. As such the variable for patient satisfaction at GP Practice X reads " 91 ".

Our hypothesis is that the presence of competitors will encourage GP practices to improve their service and therefore result in higher patient satisfaction scores which reflect a better quality of care that patients are able to observe.

In considering these two quality measures we note that there is a view that aspects of quality that are observable to patients would be the strongest competitive tools available to a GP practice. Given the visibility of these aspects, patients might be expected to make their choice based on these

\footnotetext{
${ }^{66}$ This is not to suggest that the decision to refer the patient is not the right one at that time, indeed the patient may demand that they are referred, rather the referral can be seen as the result of a longer period of time over which a referral became the only option available to the GP.

${ }^{67}$ If ACS referrals reflect the general quality of primary care but are not used by patients to compare quality of practice there will not be a disincentive to refer ACS cases. However if GPs believe that their PCT monitors ACS referral rates then there could be a disincentive. There are two points which mitigate this risk. Firstly the method by which ACS referrals are minimised is by regular monitoring and pro-active care for patients. By the point at which an ACS referral is necessary it will be too late for the GP to decide not to refer. Thus at that stage a referral is unavoidable. Secondly, as we explain later we have controlled for the disease prevalence amongst the registered patients. This therefore allows us to condition the ACS referral rate upon the case mix at a GP practice.

${ }^{68}$ See Carlsen, Grytten, Kjelvik and Skau: "Better primary physician services lead to fewer hospital admissions" European journal of health economics, Vol.8, March 2007, pp17-24. Also see Biorn, E and Godager G: "Does quality influence choice of general practitioner" Health Economics Research Programme at the University of Oslo, Working Paper 2008:3.

${ }^{69}$ Research recently published in the British Medical Journal has endorsed the robustness of this survey:

http://www.bmj.com/cgi/content/full/339/sep29 3/b3851. The survey has previously been used in papers such as "patient choice in general practice: the implications of patient choice satisfaction surveys" Robertson, Dixon and Le Grand 2008

${ }^{70}$ The full technical report on the survey design is available at:

http://www.ic.nhs.uk/webfiles/publications/gppatientsurvey2008/GP\%20Patient\%20Survey\%20Access\%20Technical\%20Report.pdf

${ }^{71}$ Inevitably despite the efforts of Ipsos MORI to ensure that a random sample of patients was selected, the voluntary nature of participation means that the results will reflect the satisfaction levels of those patients that responded to the survey. As in any survey based analysis this suggests a degree of caution in interpreting the results. However we note that just as the most and least satisfied patients (and the most regular patients) may choose to respond to the survey, the reputation of the practice may also be more heavily influenced by the most and least satisfied (and vocal) patients.
}

\section{UNCLASSIFIED}


attributes. In contrast, clinical aspects of quality tend to be less visible and, to the extent that they are visible at all, will accumulate over time in the reputation of a GP practice.

However an alternative view is that patients ultimately care most about the clinical quality of the GP practice and care less about the customer service that they receive. As a result despite the low visibility on this clinical quality attribute, the signs of it that do exist will remain a stronger influence on how patients choose their GP practice than the level of customer service. As such a good reputation for high clinical quality might be a GP practice's most valuable asset. Furthermore as noted in the Handbook of Health Economics there is much evidence suggesting that doctors with communication skills have patients in better health. ${ }^{72}$

Different patients are likely to value some aspects of quality more than other aspects (eg access and clinical quality); however we expect that all patients are all likely to attach some positive value to each of the attributes captured by our quality measures. As a result we would expect that competition would drive improvements in both aspects of the quality measures that we examine.

\section{The econometric model}

We model the GP's decision to set quality as being a function of the characteristics of the practice and the patient's registered with the practice; the characteristics of the population in the area (the potential patients of the practice); and the level of competition that the practice faces. ${ }^{73} \mathrm{We}$ therefore specify the following model in order to explain the level of quality $\left(Q_{i}\right)$ that is provided by GP practices across England. Here i denotes each individual GP practice:

$$
\mathrm{Q}_{\mathrm{i}}=\mathrm{Comp}_{\mathrm{i}}+\mathrm{GP}_{\mathrm{i}}+\mathrm{POP}_{\mathrm{MSOA}}\left(+\mathrm{S}_{\mathrm{i}}\right)+\mu_{\mathrm{i}}
$$

The dependent variable on the left hand side of the equation is $Q_{i}$ which signifies the quality of practice $i$. The explanatory variables on the right hand side are as follows: Comp $p_{i}$ indicates the number of competitors that practice i faces ${ }^{74} ; \mathrm{GP}_{i}$ is the characteristics of the GP practice $i$; $\mathrm{POP}_{\mathrm{MSOA}}$ is the population characteristics within the middle super output area (MSOA) in which the GP is located. $S_{i}$ are the characteristics profile for those patients that take part in the survey from which we obtain the patient satisfaction variable. Finally $\mu_{i}$ is the error term. We examine the variables in detail below.

\footnotetext{
${ }^{72}$ Handbook of Health Economics Volume 1B pp1179 citing Ong (1995), Kaplan et al. (1989), Wartman et al. (1983) and Stewart (1995)

${ }^{73}$ This type of econometric analysis is a long standing component of the analysis conducted by competition authorities, economic consultants, and academic competition economists. For a summary of the use of concentration analysis see http://www.competitioncommission.org.uk/our_role/analysis/pc analysis merger_cases.pdf). For example, the investigations by UK competition authorities into funeral parlours (1995), supermarkets (2000 and 2006), the banking sector (1999), cinemas (2006) and pharmacies (see the basic analysis conducted by Frontier Economics during the OFT inquiry into Pharmacies: http://www.oft.gov.uk/shared_oft/reports/comp_policy/oft609annexem.pdf). For examples in the academic literature see: Pinske et al. (2002); Manuszak and Moul (2006a), re-examining the classical FTC vs. Staples decision; Manuszak and Moul (2006b) for retail gasoline; Borenstein (1989, 1990), Morisson and Winston (1990), Brueckner et al. (1992), Evans and Kessides (1993), Kim and Singal (1996), Singal (1996) for airfares on specific routes; Neumark and Sharpe (1992), Hannan (1992), Cyrnak and Hannan (1999) for banking; and Davis $(2005,2006)$ for US movie theatres.

${ }^{74}$ This is necessarily a structural measure of competition (it quantifies the structure by counting competitors) and cannot capture the intensity of competition which may have evolved in different geographic areas as the culture of competition develops in the NHS.
}

UNCLASSIFIED 
Data

Our dataset includes data on each of the 8,230 GP practices operating in England in 2009. In addition we have collected location data on an additional 2,152 branch practices and linked these to the GP practice that provides primary care from that location.

The two measures that we have on quality are described above. Table 1 below provides descriptive statistics for the data. Figure 1 and Figure 2 illustrate the distributions of these variables.

Table 1. Summary statistics on dependent variables

\begin{tabular}{lcccc} 
& Mean & Std. Dev. & Min & Max \\
\hline ACS spells & 138 & 95.16 & 1 & 925 \\
\hline \% satisfied with care & 90.98 & 6.23 & 53 & 100 \\
\hline
\end{tabular}

Figure 1. Distribution of ACS spells

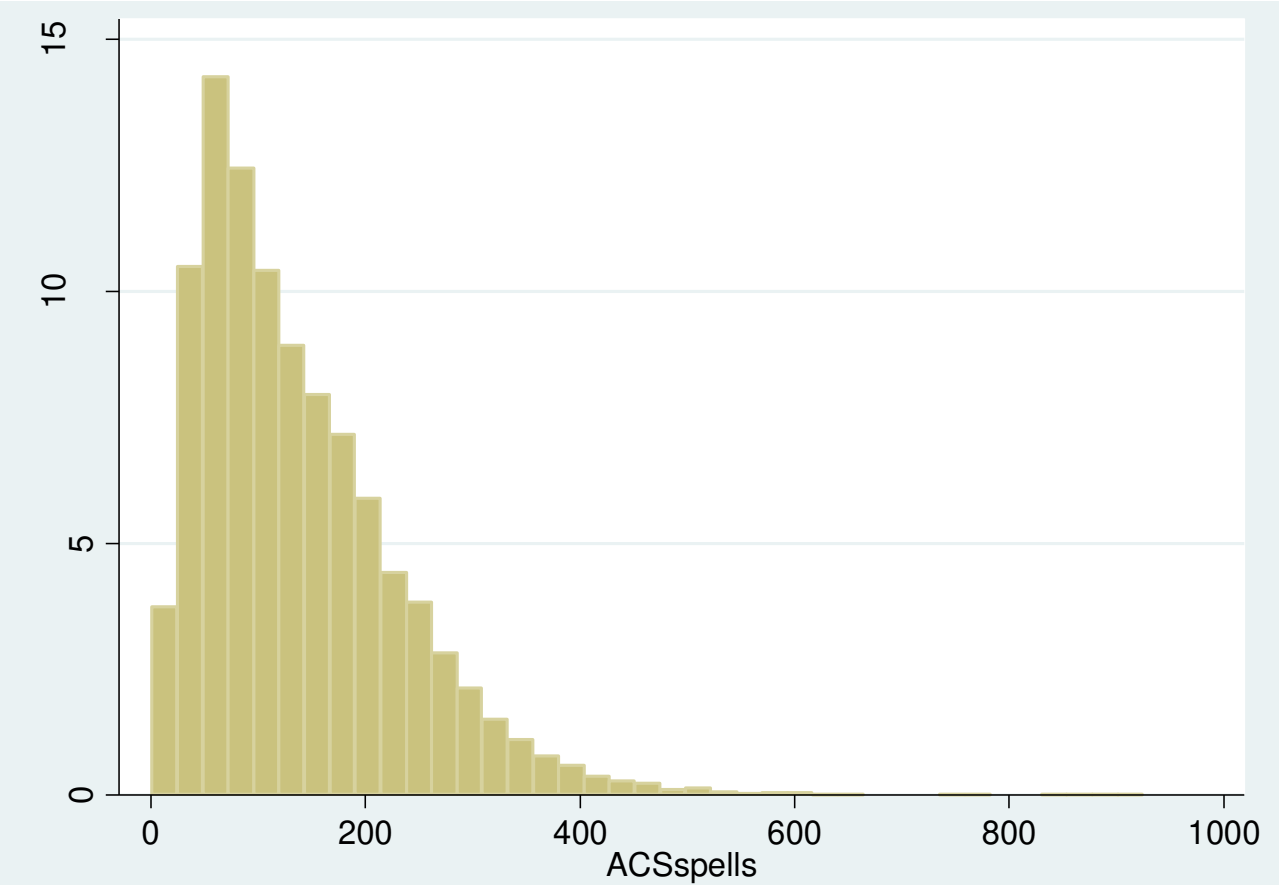


Figure 2. Distribution of \% satisfied with care (v101)

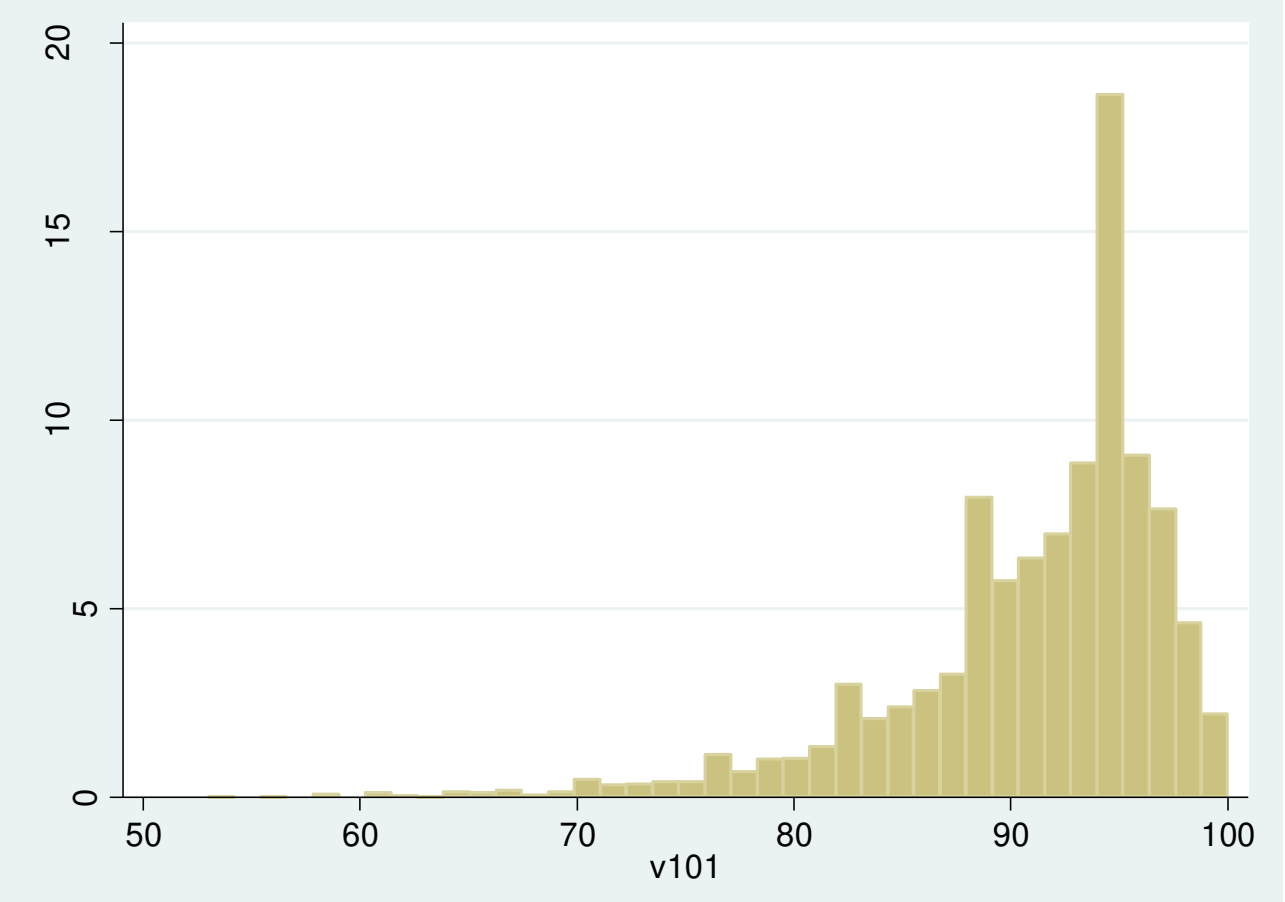

Out of interest we have also examined whether competition has any effect on QOF scores. Figure 3 below illustrates the lack of variation in QOF scores.

Figure 3. Distribution of QOF scores

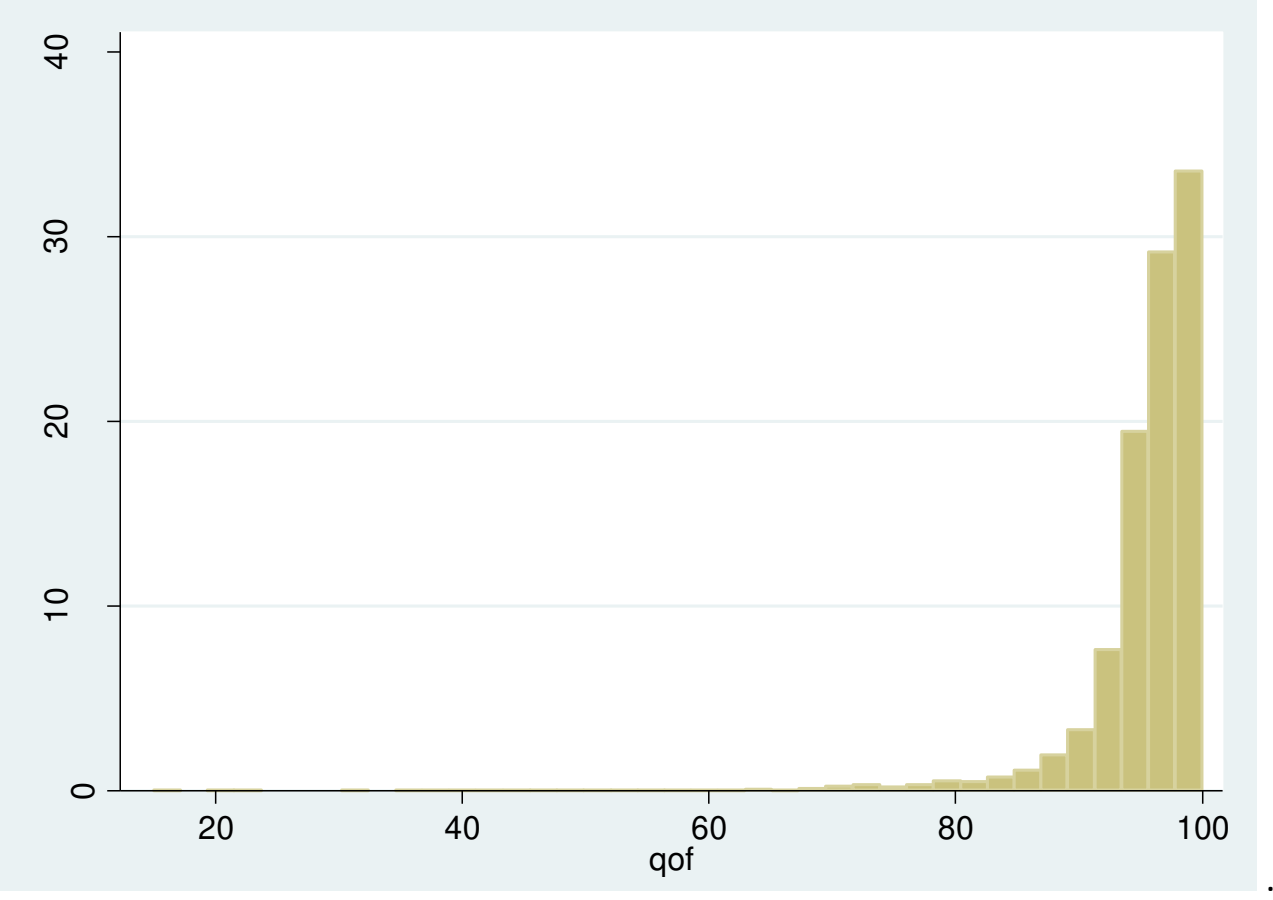

The variables that explain variation in the quality measures are described below.

\section{UNCLASSIFIED}




\section{Competitive variables}

We count the number of rival GP practices within defined (straight line) distance bands. We use these counts as an indicator of the degree of competition that the GP practice faces within that distance band. Given the importance of geographic location to patients ${ }^{75}$ we consider this to be a good approximation of the degree of competition that a GP practice faces. However our results might also indicate the potential impact of changes in the intensity of competition between GP practices located in fixed locations as well as the impact of changes in the number of competitors in an area.

The competitive variable "Comp0_500m" counts the number of competitors within 500 metres. $^{76}$ Similarly "Comp500_1000m" counts the number of additional competitors that are situated more than 500 metres away, but less than 1000 metres away. See figure 4 below. We use distance bands up to a maximum distance of 5000 metres.

Figure 4. Example diagram of GP distribution

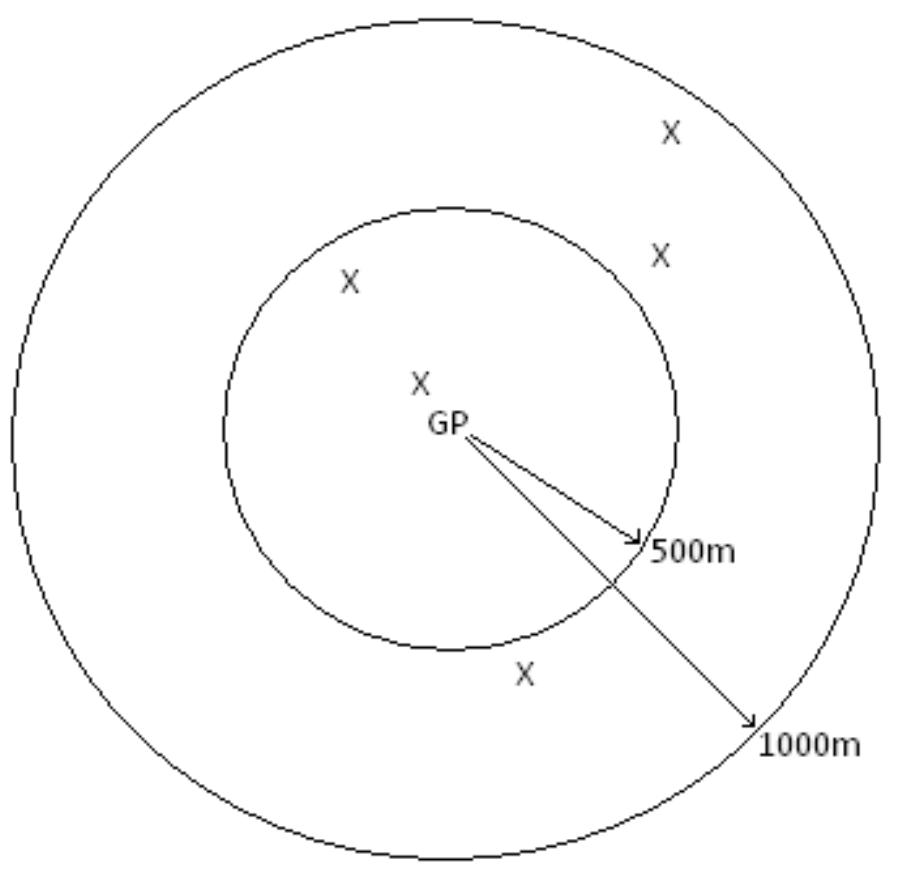

Notes: $\mathrm{GP}=\mathrm{GP}$ Practice $\mathrm{i} ; \mathrm{X}=$ rival $\mathrm{GP}$ practices (including rival branch practices) In this example: Comp0_500m =2; and, Comp500_1000m = 3 .

\footnotetext{
${ }^{75}$ See Salisbury 1989 and Robertson, Dixon \& Le Grand 2008

${ }^{76}$ These competitors might be rival GP practices or a branch practice belonging to a rival GP practice.
} 
In approximately 30 percent of cases a practice operates from one or more additional branch surgeries in addition to the practice branch surgery (see figure 5). We do not count the practice's own branches as competitors.

Figure 5. No. branches operated by each GP practice

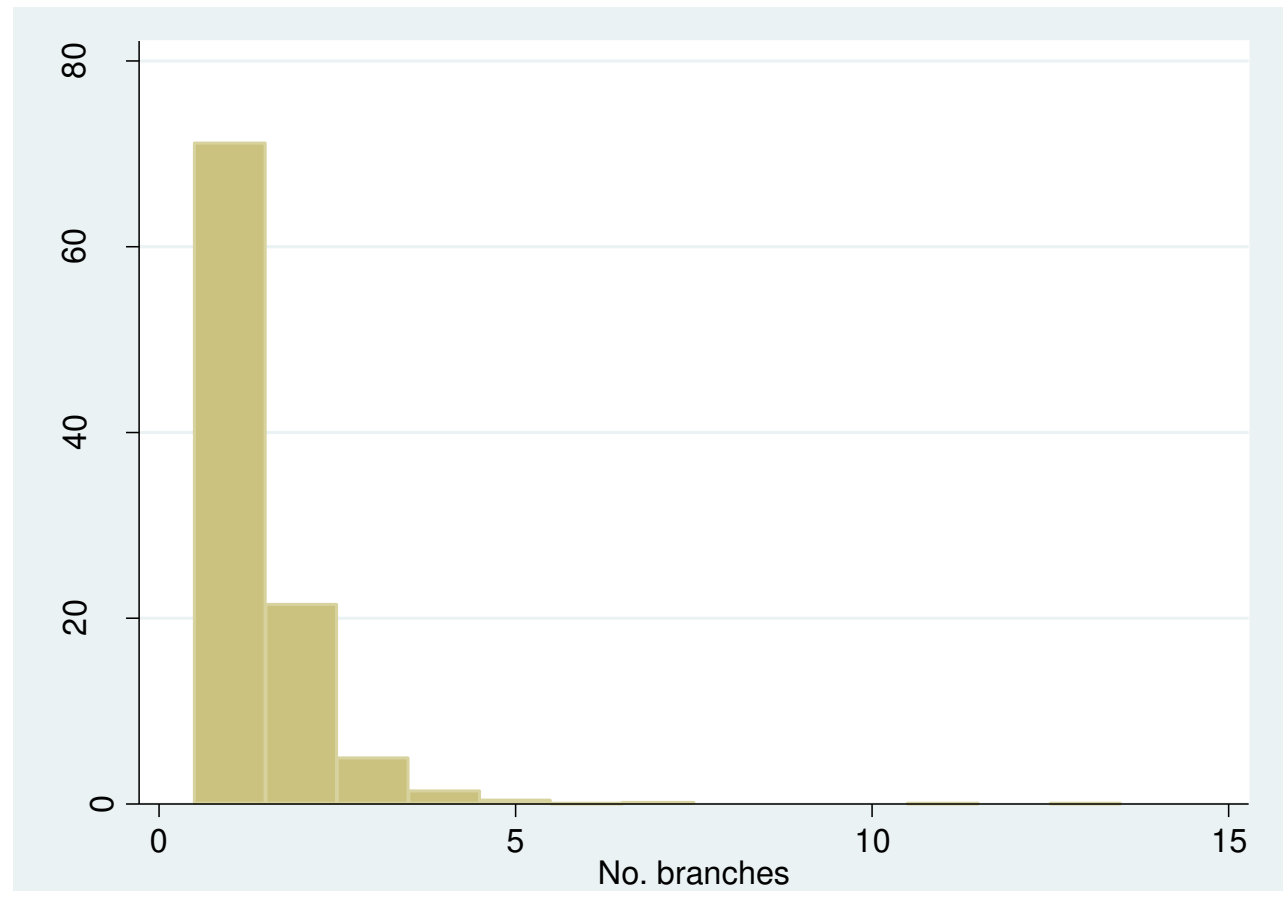

Table 2 shows the average number of competitors by distance band. As the distance band increases the size of the area (in square metres) covered by each subsequent band naturally increases. As a result we naturally see the number of competitors in each size band increasing. The distribution of competitors within 500 metres is also illustrated in Figure 6.

Table 2. Summary statistics on competition variables

\begin{tabular}{lccc} 
Variable & Mean & Std. Dev. & Max \\
\hline Comp0_500m & 1.14 & 1.520 & 10 \\
\hline Comp500_1000m & 1.58 & 2.214 & 17 \\
\hline Comp1000_1500m & 2.25 & 3.128 & 27 \\
\hline Comp1500_2000m & 2.91 & 3.881 & 26 \\
\hline Comp2000_2500m & 3.39 & 4.494 & 36 \\
\hline Comp2500_3000m & 3.89 & 5.195 & 40 \\
\hline Comp3000_3500m & 4.45 & 6.017 & 46 \\
\hline Comp3500_4000m & 4.87 & 6.680 & 45 \\
\hline Comp4000_4500m & 5.36 & 7.356 & 47 \\
\hline
\end{tabular}


Figure 6. No. Competitors within 500 metres

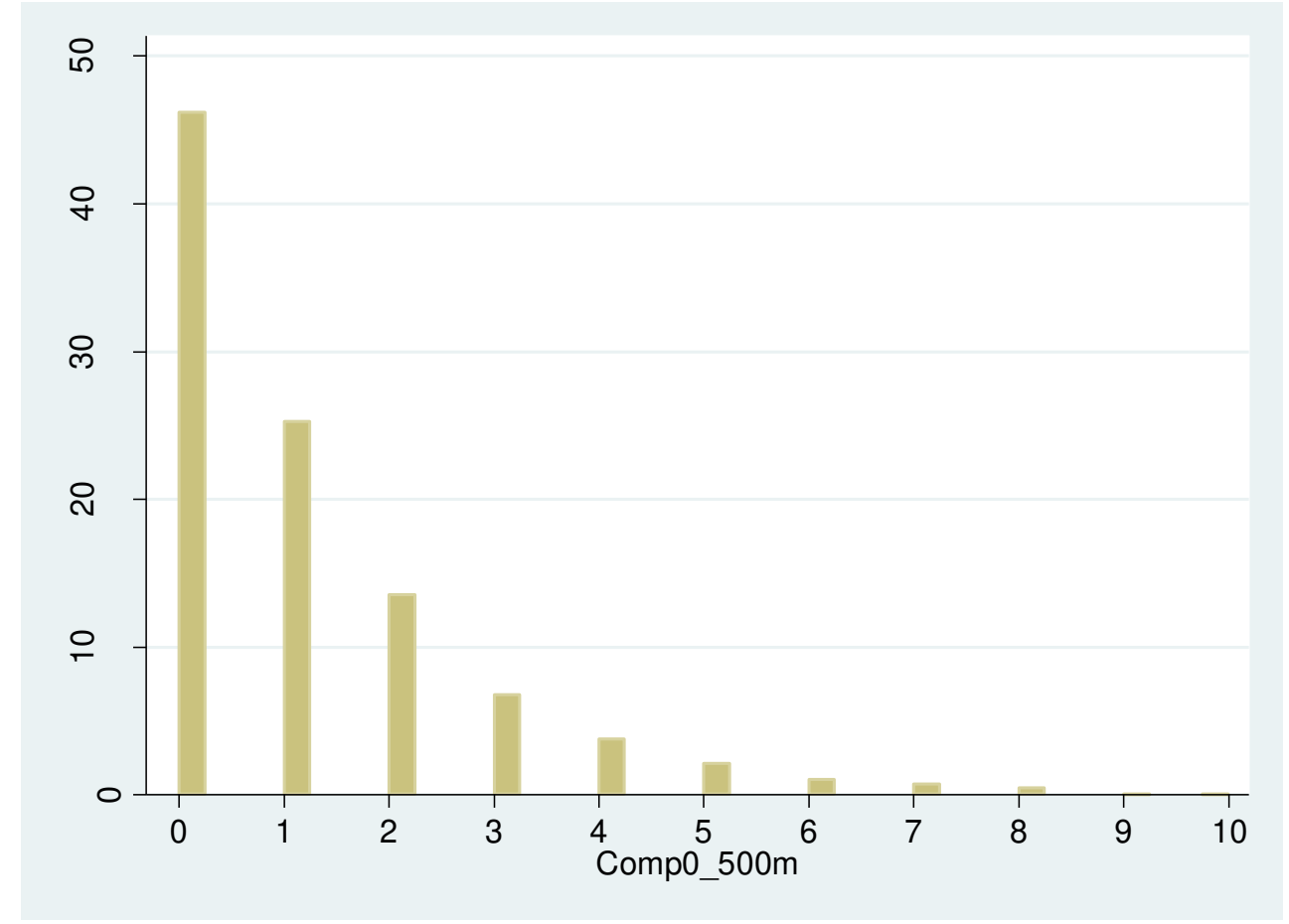

\section{Characteristics of the GP practice}

The characteristics of a GP practice that we measure include: the number of patients registered at the practice (which is often referred to as the list size); the number of GPs working at the practice; the type of location (eg whether it is in an urban or rural location, whether it is isolated or near to a population centre); the SHA that is responsible for the practice; and, the disease prevalence amongst patients registered at the practice.

Figure 7 shows the distribution of the list size variable (number of patients registered with practice i). The median list size is approximately 5,680 patients. 
Figure 7. Number of patients registered with each GP practice

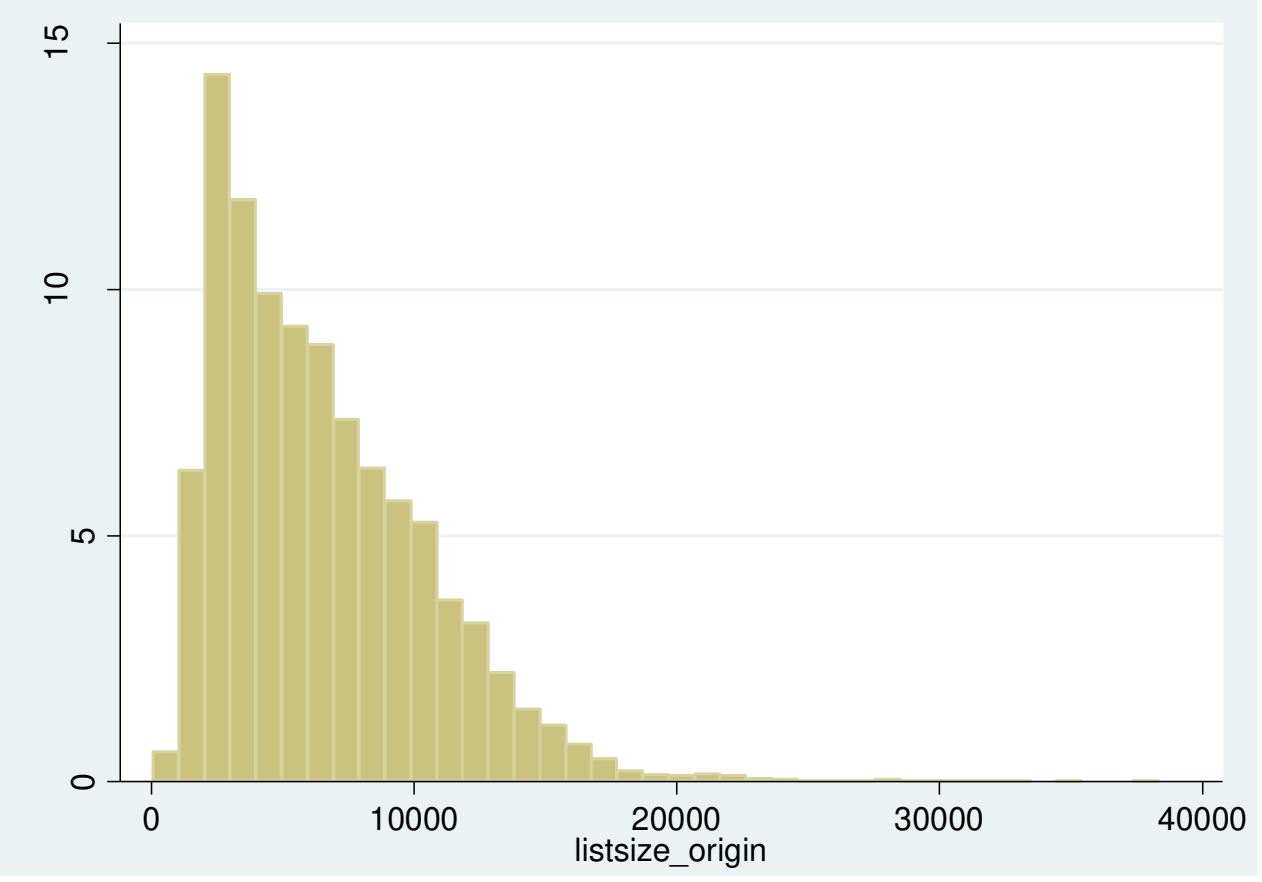

Figure 8 below shows the number of GPs working at each practice in the dataset. There are still a number of "single-hander" practices being operated by just one GP.

Figure 8. Number of GPs working at each GP practice

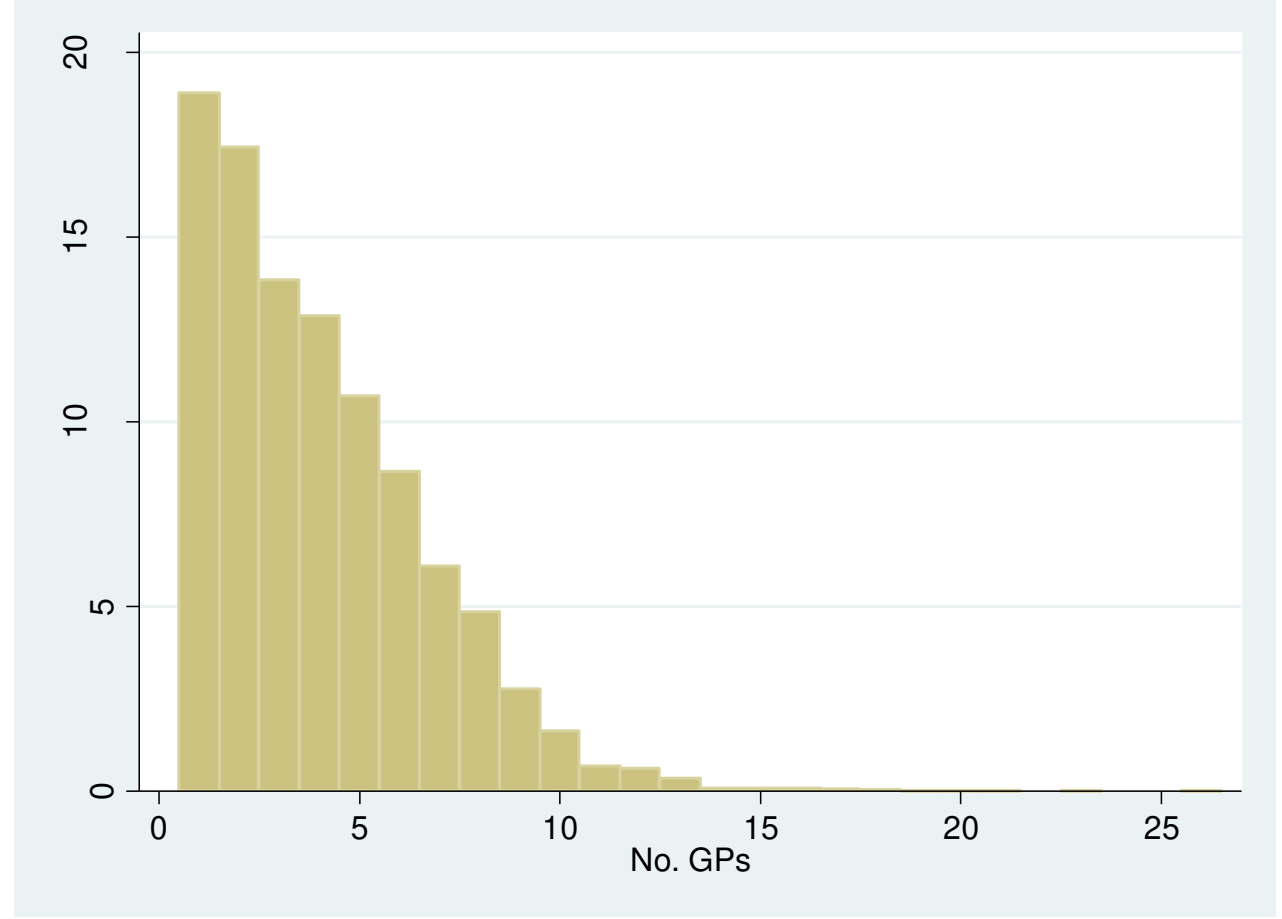


We include 7 dummies for the 8 different types of geographic classification used by the office of national statistics. We use UR1 as the base category in the regression. Hence the effect of being located in a different geographic classification is expressed in relation to UR1.

Table 3. Summary statistics on geographic classification variables

\begin{tabular}{|l|l|l|l|}
\hline Category & Percentage & Description & Example \\
\hline UR1 & $0.16 \%$ & $\begin{array}{l}\text { Urban settlements with a population of 10,000 or more } \\
\text { and the wider surrounding area is sparsely populated }\end{array}$ & $\begin{array}{l}\text { Penrith } \\
\text { (Cumbria) }\end{array}$ \\
\hline UR2 & $0.94 \%$ & $\begin{array}{l}\text { Small Town and Fringe areas and the wider surrounding } \\
\text { area is sparsely populated }\end{array}$ & $\begin{array}{l}\text { Seaton } \\
\text { (Devon) }\end{array}$ \\
\hline UR3 & $0.83 \%$ & $\begin{array}{l}\text { Village and the wider surrounding area is sparsely } \\
\text { populated }\end{array}$ & $\begin{array}{l}\text { Dungeness } \\
\text { (Kent) }\end{array}$ \\
\hline UR4 & $0.11 \%$ & $\begin{array}{l}\text { Hamlet \& Isolated Dwelling and the wider surrounding } \\
\text { area is sparsely populated }\end{array}$ & $\begin{array}{l}\text { Launceston } \\
\text { (Cornwall) }\end{array}$ \\
\hline UR5 & $79.49 \%$ & $\begin{array}{l}\text { Urban settlements with a population of 10,000 or more } \\
\text { and the wider surrounding area is less sparsely populated }\end{array}$ & $\begin{array}{l}\text { Coventry } \\
\text { (Midlands) }\end{array}$ \\
\hline UR6 & $12.23 \%$ & $\begin{array}{l}\text { Small Town and Fringe areas and the wider surrounding } \\
\text { area is less sparsely populated }\end{array}$ & $\begin{array}{l}\text { Cromer } \\
\text { (Norfolk) }\end{array}$ \\
\hline UR7 & $5.57 \%$ & $\begin{array}{l}\text { Village and the wider surrounding area is less sparsely } \\
\text { populated }\end{array}$ & $\begin{array}{l}\text { Ampleforth } \\
\text { (Yorkshire) }\end{array}$ \\
\hline UR8 & $0.66 \%$ & $\begin{array}{l}\text { Hamlet \& Isolated Dwelling and the wider surrounding } \\
\text { area is less sparsely populated }\end{array}$ & $\begin{array}{l}\text { Lambourne } \\
\text { (Berkshire) }\end{array}$ \\
\hline
\end{tabular}

We include 9 dummies for the 10 different Strategic Health Authorities (SHAs) in England. We use SHA1 (North East SHA) as the base in the regression. Hence the effect of being located in a different SHA is expressed in relation to North East SHA.

Table 4. Summary statistics on SHA variables

\begin{tabular}{|l|c|c|}
\hline & SHA & Percentage of GPs \\
\hline SHA1 & North East & $5.20 \%$ \\
\hline SHA2 & North West & $14.23 \%$ \\
\hline SHA3 & Yorkshire \& Humber & $10.51 \%$ \\
\hline SHA4 & East Midlands & $8.11 \%$ \\
\hline SHA5 & West Midlands & $11.13 \%$ \\
\hline SHA6 & East of England & $10.10 \%$ \\
\hline SHA7 & London & $16.44 \%$ \\
\hline SHA8 & South East & $8.32 \%$ \\
\hline SHA9 & South Central & $6.17 \%$ \\
\hline SHA10 & South West & $9.78 \%$ \\
\hline
\end{tabular}

We also measure the degree of disease (or condition) prevalence amongst patients registered at the practice. ${ }^{77}$ High prevalence of a given disease might be expected to make it more difficult for the GP to deliver high quality outcomes. High prevalence of conditions will increase the likelihood of ACS

${ }^{77}$ Source: NHS Information centre

\section{UNCLASSIFIED}


referrals regardless of the quality of primary care that the GP delivers. Therefore we want to consider quality after adjusting for patient-mix. Higher prevalence may also reduce the capacity of a GP practice and thereby affect the ability of patients to get appointments.

Table 5. Summary statistics disease prevalence variables

\begin{tabular}{|l|c|c|}
\hline & $\begin{array}{c}\text { Mean variable value: } \\
\text { Percentage prevalence of } \\
\text { disease on practice list (\%) }\end{array}$ & Max (\%) \\
\hline Coronary Heart Disease & 3.47 & 20.8 \\
\hline Hypertension & 13.22 & 52 \\
\hline Stroke or Transient Ischaemic Attacks & 1.61 & 23.5 \\
\hline Chronic Obstructive Pulmonary Disease & 1.57 & 8.6 \\
\hline Hypothyroidism & 2.79 & 13.9 \\
\hline Cancer & 1.21 & 5.3 \\
\hline Mental Health & 0.79 & 23.8 \\
\hline Asthma & 5.82 & 19 \\
\hline Heart Failure & 0.73 & 6.9 \\
\hline Heart Failure due to LVD & 0.38 & 3.7 \\
\hline Palliative Care & 0.10 & 1.6 \\
\hline Dementia & 0.43 & 48 \\
\hline Depression & 7.51 & 48.1 \\
\hline Atrial Fibrillation & 1.28 & 10.9 \\
\hline CKD & 3.92 & 40.6 \\
\hline Diabetes & 5.24 & 19.6 \\
\hline Epilepsy & 0.76 & 4.9 \\
\hline Learning Disability & 0.38 & 5.9 \\
\hline Obesity & 10.39 & 48.6 \\
\hline
\end{tabular}

\section{Population characteristics}

Characteristics of the local population include the age profile of the local population, and indicators of population changes in the local area, these occur as a result of changes to the rate of births, deaths, and net population flows (eg house moves). We measure each of these at the level of the middle super output area (MSOA) in which the GP is located. These MSOAs include a typical population of approximately 3,000 people.

Table 6. Summary statistics on age profiles of middle super output areas across England

\begin{tabular}{|l|c|c|c|}
\hline Age band & Mean variable value & Min & Max \\
\hline $0-15$ & $18.79 \%$ & $2.36 \%$ & $36.19 \%$ \\
\hline $16-29$ & $19.42 \%$ & $7.04 \%$ & $80.98 \%$ \\
\hline $30-44$ & $21.76 \%$ & $5.40 \%$ & $42.10 \%$ \\
\hline $45-$ retirement age & $21.41 \%$ & $4.60 \%$ & $32.16 \%$ \\
\hline Retirement age & $18.62 \%$ & $2.78 \%$ & $50.93 \%$ \\
\hline
\end{tabular}

UNCLASSIFIED 
Table 7. Summary statistics on age profiles of middle super output areas across England

\begin{tabular}{|l|c|c|c|}
\hline & Mean variable value & Min & Max \\
\hline Birth rate (per `000) & 13.3673 & 1.4301 & 37.1002 \\
\hline Death rate (per `000) & 9.505 & 0.9113 & 29.7885 \\
\hline Net population flow (per '000) & -0.2492 & -26.2089 & 18.9961 \\
\hline
\end{tabular}

\section{Surveyed patient characteristics}

Finally we have data on the particular characteristics of the patients that responded to the patient satisfaction survey. These characteristics are likely to be correlated with the responses to the questionnaire. Hence in explaining the level of quality observed by patients we include data on: whether the respondents have tried to access their GP in the last 6 months; the working status of the respondents, and the state of health of the respondents (self-assessed).

Table 8. Survey questions on the characteristics of the respondent to the survey

\begin{tabular}{|l|}
\hline Survey question: \\
\hline \% tried to see a doctor fairly quickly in past 6 months \\
\hline \% tried to book ahead to see a doctor in past 6 months \\
\hline Working status: \% working full time \\
\hline Working status: \% part-time work \\
\hline Working status: \% full-time education \\
\hline Working status: \% Unemployed \\
\hline Working status: \% looking after the home \\
\hline State of health: \% excellent \\
\hline State of health: \% very good \\
\hline State of health: \% good \\
\hline State of health: \% poor \\
\hline
\end{tabular}

Note that we do not include the variable that counts the number of respondents that self assess their health as "fair". This is taken as the base against which the estimated coefficients on the remaining "state of health" variables will be interpreted. Similarly we do not include the variable that counts the number of respondents that are retired, permanently sick or disabled. This is therefore the base against which the estimated coefficients on the remaining "Working status" variables will be interpreted. 


\section{Results}

We estimated the model specified in equation (1) by OLS, using our two measures of the quality of service provided at a GP practice: firstly clinical aspects of quality that are not immediately visible to the patient (as captured by the number of ACS referrals to acute hospitals); and, secondly those aspects of quality visible to the patient (as captured in the GP patient satisfaction survey).

ACS spells

The results that we obtained from the ACS referral regression are as follows:

Table 9. Regression results: ACS referrals made by the Practice

\begin{tabular}{lrrr} 
Dependent variable: ACS referrals made by the Practice & Coefficient & t-statistic & Prob. >t \\
\hline Comp0_500m & -0.7080 & $\mathbf{- 2 . 2 0}$ & 0.028 \\
\hline Comp500_1000m & -0.0501 & -0.19 & 0.851 \\
\hline Comp1000_1500m & -0.0827 & -0.38 & 0.702 \\
\hline Comp1500_2000m & 0.1525 & 0.78 & 0.436 \\
\hline Comp2000_2500m & 0.2006 & 1.18 & 0.239 \\
\hline Comp2500_3000m & 0.2852 & 1.68 & 0.093 \\
\hline Comp3000_3500m & 0.0678 & 0.44 & 0.659 \\
\hline Comp3500_4000m & 0.2684 & 1.82 & 0.068 \\
\hline Comp4000_4500m & 0.2216 & 1.65 & 0.099 \\
\hline Comp4500_5000m & 0.1794 & 1.43 & 0.152 \\
\hline No. GPs in the practice & 2.8411 & $\mathbf{7 . 3 3}$ & 0 \\
\hline List size & 0.0212 & $\mathbf{5 3 . 8 1}$ & 0 \\
\hline List size sq & 0.0000 & -6.84 & 0 \\
\hline Age weight: percent0_15 & 81.6016 & $\mathbf{3 . 3 7}$ & 0.001 \\
\hline Age weight: percent16_29 & 24.2498 & 1.30 & 0.194 \\
\hline Age weight: percent30_44 & -36.3554 & -1.70 & 0.089 \\
\hline Age weight: percent45_ret & 65.9449 & $\mathbf{1 . 9 9}$ & 0.047 \\
\hline MSOA: net change (per '000) & -0.2439 & -0.98 & 0.327 \\
\hline MSOA: birth rate (per '000) & 1.0454 & $\mathbf{5 . 3 7}$ & 0 \\
\hline MSOA: death rate (per '000) & 1.3255 & $\mathbf{6 . 7 6}$ & 0 \\
\hline Urban/Rural: cat 2 & 24.5735 & $\mathbf{2 . 1 9}$ & 0.029 \\
\hline Urban/Rural: cat 3 & 24.9717 & $\mathbf{2 . 0 3}$ & 0.042 \\
\hline Urban/Rural: cat 4 & 23.2825 & 1.34 & 0.18 \\
\hline Urban/Rural: cat 5 & 38.8757 & $\mathbf{3 . 7 8}$ & 0 \\
\hline Urban/Rural: cat 6 & 27.4352 & $\mathbf{2 . 6 5}$ & 0.008 \\
\hline Urban/Rural: cat 7 & 32.3851 & $\mathbf{3 . 0 5}$ & 0.002 \\
\hline Urban/Rural: cat 8 & 26.6179 & $\mathbf{2 . 1 5}$ & 0.032 \\
\hline SHA2 (North West) & -0.6951 & -0.29 & 0.774 \\
\hline SHA3 (Yorkshire \& Humber) & -8.2933 & $\mathbf{- 3 . 1 6}$ & 0.002 \\
\hline SHA4 (East Midlands) & -13.9851 & $-\mathbf{5 . 0 2}$ & 0 \\
\hline & & & \\
\hline
\end{tabular}

UNCLASSIFIED 


\begin{tabular}{|c|c|c|c|}
\hline SHA5 (West Midlands) & -29.8985 & -11.19 & 0 \\
\hline SHA6 (East of England) & -23.4050 & -8.38 & 0 \\
\hline SHA7 (London) & -31.3278 & -10.00 & 0 \\
\hline SHA8 (South East) & -34.3457 & -11.88 & 0 \\
\hline SHA9 (South Central) & -26.3782 & -8.77 & 0 \\
\hline SHA10 (South West) & -13.8466 & -4.96 & 0 \\
\hline Prevalence: Coronary Heart Disease & 6.9617 & 8.24 & 0 \\
\hline Prevalence: Hypertension & -0.2900 & -1.22 & 0.222 \\
\hline Prevalence: Stroke or Transient Ischaemic Attacks & 3.3213 & 2.68 & 0.007 \\
\hline Prevalence: Chronic Obstructive Pulmonary Disease & 10.5901 & 12.66 & 0 \\
\hline Prevalence: Hypothyroidism & -2.4949 & -3.44 & 0.001 \\
\hline Prevalence: Cancer & -3.6292 & -2.57 & 0.01 \\
\hline Prevalence: Mental Health & 0.9064 & 0.91 & 0.363 \\
\hline Prevalence: Asthma & 0.2702 & 0.68 & 0.5 \\
\hline Prevalence: Heart Failure & 0.2795 & 0.11 & 0.913 \\
\hline Prevalence: Heart Failure due to LVD & -0.2713 & -0.09 & 0.928 \\
\hline Prevalence: Palliative Care & -6.1444 & -1.53 & 0.127 \\
\hline Prevalence: Dementia & -4.8175 & -6.16 & 0 \\
\hline Prevalence: Depression & 0.1730 & 1.50 & 0.134 \\
\hline Prevalence: Atrial Fibrillation & -0.4988 & -0.30 & 0.765 \\
\hline Prevalence: CKD & -0.3970 & -1.60 & 0.109 \\
\hline Prevalence: Diabetes & 4.9417 & 11.54 & 0 \\
\hline Prevalence: Epilepsy & 23.3174 & 10.72 & 0 \\
\hline Prevalence: Learning Disability & 3.6304 & 2.15 & 0.032 \\
\hline Prevalence: Obesity & 0.6181 & 4.16 & 0 \\
\hline constant & -162.3489 & -7.76 & 0 \\
\hline
\end{tabular}

\begin{tabular}{lr}
\hline Number of observations & 7968 \\
\hline R-squared & 0.8292 \\
\hline
\end{tabular}

Notes: Statistically significant results at the $5 \%$ level are in bold. Urban/rural, SHA and age weight variables each have a base variable which is excluded from the regression (ie Urban/Rural cat 1; SHA1; Age weight: percent retired)

The key result here is the coefficient on the number of competitors between 0 and 500 metres. This is negative and therefore shows that practices with more rival GP practices nearby offer a better clinical standard of service and so make fewer referrals to acute hospitals for ACS conditions. This benefit of competition is valuable since it keeps patients healthier and out of hospital, and saves the taxpayer the cost of providing expensive acute treatment.

The coefficient on the "Comp0_500m" variable is -0.7080 . This means that, all else being equal, the presence of an additional rival within 500 metres is associated with 0.7 less ACS referrals by the GP practice in question each year. For context the average number of ACS referrals each year is 138 . None of the other competitive variables are statistically significant.

\section{UNCLASSIFIED}


Notably the more GPs working at a practice the more ACS referrals a practice makes. If the additional GPs are younger salaried workers this might reflect less experience, or it might reflect the lack of relationship between patient and GP when there are multiple GPs at a practice and patients see a different GP each time they come in. This might discourage a given GP from taking full responsibility for the overall health of a patient in the same way as smaller GP practices might have to $^{78}$.

Other results on practice characteristics include the following:

a) Practices with a larger proportion of children referred more ACS cases than those with a smaller proportion of children. This might indicate that certain ACS conditions are more prevalent amongst children or that GPs are more likely to refer children, perhaps due to parental anxiety.

b) Areas with larger birth and death rates saw more ACS referrals. This might be taken to reflect the increased workload associated with treating babies and those with terminal illnesses.

c) GP practices with a higher proportion of patients suffering from cancer, hypothyroidism and dementia each referred fewer patients for ACS conditions.

d) GP practices with a higher proportion of patients suffering from coronary heart disease, strokes, COPD, diabetes and epilepsy each refer more patients for ACS conditions. This is to be expected since these are ACS conditions and these patients are therefore unsurprisingly likely to be particularly vulnerable to ACS referrals regardless of the clinical quality of their GP in question. ${ }^{79}$

e) A larger list size is associated with more ACS referrals. Again this is likely to mean that larger list sizes will include greater numbers of patients that are vulnerable to ACS referrals (despite the proportion of patients being vulnerable to ACS referrals remaining the same).

To test the robustness of these findings we ran a further specification of the model. This firstly examines the number of ACS referrals per patient registered at practice $i$. This addresses the possibility that controlling for list size and list size squared might not adequately capture the natural increase in ACS referrals as list size increases. Secondly we change the explanatory variable from number of GPs at practice $i$ to number of GPs per patient at practice $i$. This addresses the possibility that the list size and the number of GPs are correlated.

\footnotetext{
${ }^{78}$ An alternative possibility emerges from one robustness check in which we replaced the variable counting the number of GPs at a practice with a variable that measures the number of GPs per patient registered at a practice. In contrast to the positive coefficient on the absolute number of GPs variable, the coefficient on this measure is insignificant. Notably however this change does not affect the other estimated coefficients (in particular the coefficients on the competitive variables).

${ }^{79}$ Controlling for the prevalence of these conditions therefore standardises the number of ACS referrals that would be expected at a given GP practice. The full set of ACS conditions are as follows: angina; asthma ; cellulitis; chronic obstructive pulmonary disease (COPD); congestive heart failure; convulsions \& epilepsy; dehydration \& gastroenteritis; dental conditions; diabetes complications; ENT infections; gangrene; hypertension; Influenza and pneumonia; iron deficiency anaemia; nutrional deficiencies; other vaccine; pelvic inflammatory disease; perforated/bleeding ulcer; and, pyelonephritis
} 
The results of this second specification are set out in table 10 below (the new variables are highlighted in bold):

Table 10. Regression results: ACS referrals per patient registered at the Practice that are made by the Practice

\begin{tabular}{|c|c|c|c|}
\hline $\begin{array}{l}\text { Dependent variable: ACS referrals per patient } \\
\text { registered at the Practice }\end{array}$ & Coefficient & t-statistic & Prob. $>t$ \\
\hline Comp0_500m & -0.0895 & -1.97 & 0.049 \\
\hline Comp500_1000m & -0.0504 & -1.34 & 0.181 \\
\hline Comp1000_1500m & -0.0248 & -0.81 & 0.419 \\
\hline Comp1500_2000m & -0.0212 & -0.77 & 0.444 \\
\hline Comp2000_2500m & 0.0373 & 1.55 & 0.122 \\
\hline Comp2500_3000m & 0.0436 & 1.82 & 0.069 \\
\hline Comp3000_3500m & 0.0381 & 1.75 & 0.08 \\
\hline Comp3500_4000m & 0.0205 & 0.99 & 0.324 \\
\hline Comp4000_4500m & 0.0335 & 1.77 & 0.077 \\
\hline Comp4500_5000m & 0.0240 & 1.36 & 0.175 \\
\hline No. GPs per patient & 286.5443 & 3.59 & 0 \\
\hline List size & 0.000006 & 0.14 & 0.89 \\
\hline List size sq & -0.000000002 & -0.78 & 0.438 \\
\hline Age weight: percent0_15 & 18.6178 & 5.43 & 0 \\
\hline Age weight: percent16_29 & 3.5266 & 1.34 & 0.181 \\
\hline Age weight: percent30_44 & -12.7282 & -4.21 & 0 \\
\hline Age weight: percent45_ret & -4.7951 & -1.02 & 0.307 \\
\hline MSOA: net change (per ‘000) & 99.7299 & 2.84 & 0.005 \\
\hline MSOA: birth rate (per ‘000) & 86.2413 & 3.13 & 0.002 \\
\hline MSOA: death rate (per ‘000) & 166.0899 & 5.99 & 0 \\
\hline Urban/Rural: cat 2 & 3.0766 & 1.94 & 0.052 \\
\hline Urban/Rural: cat 3 & 2.7520 & 1.59 & 0.113 \\
\hline Urban/Rural: cat 4 & 0.2882 & 0.12 & 0.907 \\
\hline Urban/Rural: cat 5 & 5.0567 & 3.48 & 0 \\
\hline Urban/Rural: cat 6 & 3.8286 & 2.62 & 0.009 \\
\hline Urban/Rural: cat 7 & 3.0868 & 2.06 & 0.039 \\
\hline Urban/Rural: cat 8 & 4.4360 & 2.54 & 0.011 \\
\hline SHA2 (North West) & 0.7522 & 2.21 & 0.027 \\
\hline SHA3 (Yorkshire \& Humber) & -0.5338 & -1.44 & 0.15 \\
\hline SHA4 (East Midlands) & -2.0407 & -5.2 & 0 \\
\hline SHA5 (West Midlands) & -3.8845 & -10.33 & 0 \\
\hline SHA6 (East of England) & -2.9165 & -7.4 & 0 \\
\hline
\end{tabular}




\begin{tabular}{|c|c|c|c|}
\hline SHA7 (London) & -4.8361 & -10.94 & 0 \\
\hline SHA8 (South East) & -4.9251 & -12.09 & 0 \\
\hline SHA9 (South Central) & -3.0213 & -7.11 & 0 \\
\hline SHA10 (South West) & -1.8202 & -4.62 & 0 \\
\hline Prevalence: Coronary Heart Disease & 1.0427 & 8.74 & 0 \\
\hline Prevalence: Hypertension & -0.0715 & -2.13 & 0.033 \\
\hline Prevalence: Stroke or Transient Ischaemic Attacks & 0.3434 & 1.96 & 0.05 \\
\hline Prevalence: Chronic Obstructive Pulmonary Disease & 2.2607 & 19.09 & 0 \\
\hline Prevalence: Hypothyroidism & -0.6741 & -6.57 & 0 \\
\hline Prevalence: Cancer & -0.9284 & -4.66 & 0 \\
\hline Prevalence: Mental Health & 1.3524 & 9.27 & 0 \\
\hline Prevalence: Asthma & 0.2000 & 3.55 & 0 \\
\hline Prevalence: Heart Failure & -0.3616 & -1.01 & 0.315 \\
\hline Prevalence: Heart Failure due to LVD & 0.1197 & 0.28 & 0.779 \\
\hline Prevalence: Palliative Care & -1.8284 & -3.21 & 0.001 \\
\hline Prevalence: Dementia & 0.9366 & 8.34 & 0 \\
\hline Prevalence: Depression & 0.0600 & 3.69 & 0 \\
\hline Prevalence: Atrial Fibrillation & -0.4857 & -2.06 & 0.039 \\
\hline Prevalence: CKD & -0.0494 & -1.41 & 0.159 \\
\hline Prevalence: Diabetes & 0.4844 & 8 & 0 \\
\hline Prevalence: Epilepsy & 3.9156 & 12.7 & 0 \\
\hline Prevalence: Learning Disability & 0.5701 & 2.38 & 0.017 \\
\hline Prevalence: Obesity & 0.0410 & 1.95 & 0.051 \\
\hline constant & 3.6317 & 1.23 & 0.22 \\
\hline Number of observations & 7968 & & \\
\hline R-squared & 0.5157 & & \\
\hline
\end{tabular}

From this second specification we can see that these adjustments have little effect on our findings on the competitive variables

The coefficient on the "Comp0_500m" variable is -0.0895 . This means that, all else being equal, the presence of an additional rival within 500 metres is associated with 0.0895 less ACS referrals per patient by the GP practice in question each. This impact of an extra competitor can be considered relative to the impact of other explanatory variables. Hence from the coefficients it can be seen that one additional competitor has the same effect on the number of ACS referrals per patient as 1,000 fewer births in the local area (middle super output area), which, all else being equal, might be expected to reduce the workload of the GP and thereby allowing them to improve the quality of primary care delivered to their patients. 


\section{Patient satisfaction}

The results that we obtained from estimating the model using patient satisfaction as a measure of quality were as follows:

Table 11. Regression results: patient satisfaction with care received

\begin{tabular}{|c|c|c|c|}
\hline Dependent variable: $\%$ satisfied with care $(100 \%=100)$ & Coefficient & t-statistic & Prob. $>$ t \\
\hline Comp0_500m & 0.1032 & 2.41 & 0.016 \\
\hline Comp500_1000m & 0.0108 & 0.31 & 0.755 \\
\hline Comp1000_1500m & -0.0326 & -1.15 & 0.248 \\
\hline Comp1500_2000m & 0.0148 & 0.60 & 0.549 \\
\hline Comp2000_2500m & 0.0027 & 0.12 & 0.902 \\
\hline Comp2500_3000m & 0.0495 & 2.24 & 0.025 \\
\hline Comp3000_3500m & -0.0334 & -1.70 & 0.09 \\
\hline Comp3500_4000m & -0.0368 & -1.94 & 0.053 \\
\hline Comp4000_4500m & -0.0069 & -0.39 & 0.693 \\
\hline Comp4500_5000m & -0.0240 & -1.50 & 0.134 \\
\hline No. GPs in the practice & 0.3561 & 6.70 & 0 \\
\hline List size & -0.0002 & -4.25 & 0 \\
\hline List size sq & 0.0000 & 0.17 & 0.861 \\
\hline Age weight: percent0_15 & 7.7155 & 2.31 & 0.021 \\
\hline Age weight: percent16_29 & 14.3275 & 5.55 & 0 \\
\hline Age weight: percent30_44 & 10.8554 & 3.47 & 0.001 \\
\hline Age weight: percent45_ret & 19.3276 & 4.14 & 0 \\
\hline MSOA: net change (per ‘000) & 0.0541 & 1.65 & 0.098 \\
\hline MSOA: birth rate (per ‘000) & -0.0227 & -0.86 & 0.39 \\
\hline MSOA: death rate (per '000) & 0.0542 & 1.99 & 0.046 \\
\hline Urban/Rural: cat 2 & 1.3187 & 0.84 & 0.402 \\
\hline Urban/Rural: cat 3 & 3.4238 & 1.95 & 0.051 \\
\hline Urban/Rural: cat 4 & 2.1507 & 0.81 & 0.415 \\
\hline Urban/Rural: cat 5 & 1.8874 & 1.33 & 0.183 \\
\hline Urban/Rural: cat 6 & 1.7477 & 1.22 & 0.221 \\
\hline Urban/Rural: cat 7 & 2.7229 & 1.86 & 0.063 \\
\hline Urban/Rural: cat 8 & 2.7980 & 1.66 & 0.097 \\
\hline SHA2 (North West) & -1.3985 & -4.20 & 0 \\
\hline SHA3 (Yorkshire \& Humber) & -0.9116 & -2.57 & 0.01 \\
\hline SHA4 (East Midlands) & -0.8585 & -2.20 & 0.028 \\
\hline SHA5 (West Midlands) & -1.3470 & -3.66 & 0 \\
\hline SHA6 (East of England) & -1.5460 & -3.93 & 0 \\
\hline SHA7 (London) & -1.3459 & -3.16 & 0.002 \\
\hline SHA8 (South East) & -2.1344 & -5.29 & 0 \\
\hline SHA9 (South Central) & -1.9108 & -4.53 & 0 \\
\hline
\end{tabular}

UNCLASSIFIED 


\begin{tabular}{|c|c|c|c|}
\hline SHA10 (South West) & -1.5040 & -3.81 & 0 \\
\hline Prevalence: Coronary Heart Disease & -0.1199 & -1.00 & 0.318 \\
\hline Prevalence: Hypertension & -0.1512 & -4.57 & 0 \\
\hline Prevalence: Stroke or Transient Ischaemic Attacks & 0.9878 & 4.83 & 0 \\
\hline Prevalence: Chronic Obstructive Pulmonary Disease & 0.6083 & 5.18 & 0 \\
\hline Prevalence: Hypothyroidism & 0.3979 & 3.92 & 0 \\
\hline Prevalence: Cancer & 0.3733 & 1.87 & 0.061 \\
\hline Prevalence: Mental Health & -1.0357 & -6.08 & 0 \\
\hline Prevalence: Asthma & 0.3475 & 6.39 & 0 \\
\hline Prevalence: Heart Failure & -1.0355 & -2.99 & 0.003 \\
\hline Prevalence: Heart Failure due to LVD & 0.6778 & 1.61 & 0.107 \\
\hline Prevalence: Palliative Care & -0.4192 & -0.75 & 0.456 \\
\hline Prevalence: Dementia & -0.3068 & -1.51 & 0.13 \\
\hline Prevalence: Depression & 0.1052 & 6.48 & 0 \\
\hline Prevalence: Atrial Fibrilation & 1.1182 & 4.57 & 0 \\
\hline Prevalence: CKD & 0.0827 & 2.39 & 0.017 \\
\hline Prevalence: Diabetes & -0.3960 & -6.57 & 0 \\
\hline Prevalence: Epliepsy & 0.5109 & 1.66 & 0.096 \\
\hline Prevalence: Learning Disabilty & 0.4314 & 1.84 & 0.066 \\
\hline Prevalence: Obesity & 0.1317 & 6.50 & 0 \\
\hline$\%$ tried to see a doctor fairly quickly in past 6 months & 0.1755 & 16.8 & 0 \\
\hline$\%$ tried to book ahead to see a doctor in past 6 months & 0.0216 & 3.02 & 0.003 \\
\hline Working status: \% working full time & -0.2354 & -14.58 & 0 \\
\hline Working status: \% part-time work & -0.0614 & -2.39 & 0.017 \\
\hline Working status: \% full-time education & -0.2219 & -10.89 & 0 \\
\hline Working status: \% Unemployed & -0.1692 & -6.87 & 0 \\
\hline Working status: \% looking after the home & -0.4143 & -15.28 & 0 \\
\hline State of health: \% excellent & 0.5369 & 19.71 & 0 \\
\hline State of health: \% very good & 0.3687 & 17.53 & 0 \\
\hline State of health: \% good & 0.1685 & 7.65 & 0 \\
\hline State of health: \% poor & -0.5461 & -2.76 & 0.006 \\
\hline constant & 52.6971 & 15.43 & 0 \\
\hline Number of observations & 5495 & & \\
\hline R-squared & 0.5359 & & \\
\hline
\end{tabular}

Notes: $\quad$ 1. There are fewer observations in this regression than the ACS regression (5495). This is a result of a large number of missing values on the surveyed patient characteristics. In particular "State of health" and Working status".

2. Statistically significant results at the $5 \%$ level are in bold. Urban/rural, SHA, age weight, working status, and state of health variables each have a base variable which is excluded from the regression (ie Urban/Rural cat 1; SHA1; Age weight percent retired; working status \% retired or permanently disabled; state of health: \% fair) 


\section{Discussion}

There are two statistically significant results in the competitive variables. Firstly additional competitors located within 0 and 500 metres are associated with patients receiving a standard of care that they are more satisfied with ${ }^{80}$.

The coefficient on the "Comp0_500m" variable is 0.1032 . This means that, all else being equal, the presence of an additional rival within 500 metres is associated with patients being 0.1 percent more satisfied with their GP practice. Unfortunately GP practice satisfaction levels are rounded to the nearest round number. However more than 3,650 practices are rated between 93 and $97 \%$ (ie within 4 percentage points). If these are uniformly distributed then a 0.1 percentage point improvement would improve the GP practice by 91 places in the GP patient satisfaction league table.

Alternatively the impact of an extra competitor can be considered relative to the impact of an additional GP. Hence from the coefficients it can be seen that one additional competitor has the same effect in improving patient satisfaction as an extra $1 / 3$ of a GP working at the Practice. Similarly the coefficients show that an extra competitor has the same effect on patient satisfaction as 500 fewer patients on the practices list size (meaning less congestion at the practice).

A second statistically significant effect is evident in one of the nine other coefficients on competitive variables, in particular the variable for the number of competitors located between 2500 and 3000 metres away ${ }^{81}$.

We have tried to identify what is driving this result but it remains unclear.

a) First we interacted the competitive variable with the eight urban/rural indicators in order to see whether the result was driven by there being different patterns of competitive interaction in different geographic types of area. Our results suggested that the effect was driven by results in urban areas (category 5 into which nearly $80 \%$ of GP practices in England are classified). This suggests that the result cannot be attributed to the existence of different patterns of competitive interaction in more rural areas.

b) Secondly we considered whether the result was driven by cases in which the rival practices, despite being 2500 to 3000 metres away, were in fact the closest rivals to GP practice i. However our results suggested that there were few such cases and they did not appear to have any significant effect in driving the $2500-3000 \mathrm{~m}$ result.

An alternative explanation is based on catchment areas. Even the definition of a restrictive catchment area cannot generally prevent patients being able to choose between practices within 500 metres of one another. This is because the catchment areas of two such proximate GP practices would almost inevitably overlap to a large extent. However as practices are located further away from one another the degree of overlap in the two catchment areas is likely to fall, meaning fewer

\footnotetext{
${ }^{80}$ The lack of correlation between this variable and the remaining competitive variables reduces possible concerns over multicollinearity. In any case we note that this would not bias our estimates.

${ }^{81}$ For context 3000 metres is (very) approximately half the breadth of an urban PCT. Each PCT tends to have 2 or 3 PBC clusters
} 
patients can actually choose between the practices. Importantly, this implies there are fewer marginal patients and hence less incentive for the practices to compete with one another.

Catchment areas can vary significantly in size. ${ }^{82}$ Unfortunately the size of a practice's catchment area is an unobserved variable in our analysis (that has proved impossible to collect). In light of these variations it is possible that there are some practices with wider catchment areas and that this brings them into competition with a wider set of GP practices than is typically the case (perhaps rivals, located further away that also have large catchment areas). It is possible therefore that the simple explanation behind the $2500-3000 \mathrm{~m}$ result is that these practices do in fact compete with rivals up to $\mathbf{3 0 0 0}$ metres away. If that were the case then we might consider that there is scope for competition to occur across a 3000 metre radius rather than a 500 metre radius. ${ }^{83}$

Other results on practice characteristics include the following:

a) More GPs working at a practice and a smaller list size are both associated with greater patient satisfaction with the care provided. This appears intuitive since both might indicate that the practice is not overworked or oversubscribed and therefore mean that it is easier to get appointments, perhaps the GPs coordinate to provide longer opening hours, and members of staff have time to explain things to patients.

b) Practices serving a larger proportion of retired patients received lower ratings than those with a smaller proportion of retirees. This might be a result of retired patients needing more of a GPs time and therefore stretching the practice's resources further and reducing the capacity it has for treating any given patient. This might reflect all patients (older and younger) preferring a practice where they can easily get an appointment.

c) Patients at practices with a higher proportion of patients suffering from certain conditions were more satisfied with their care. These diseases included: asthma; obesity; CKD; atrial fibrillation; Depression; COPD; stroke or transient ischaemic attacks; and hypothyroidism. ${ }^{84}$ It is possible that these conditions bring these patients into contact with their GP more often and therefore contribute to a better doctor-patient relationship. However, such effects might be expected to be counterbalanced if increased numbers of patients with conditions stretch the practices resources further

\footnotetext{
${ }^{82}$ Research suggests that, on average, catchment areas cover approximately 2 square miles, though they vary significantly in size (between 0.19 and 13 square miles). Jenkins (1996) finds that in one London borough poorer quality GP practices have catchment areas three times larger than higher quality GP practices. Jenkins, C and Campbell, J: "Catchment areas in general practice and their relation to size and quality of practice and deprivation: a descriptive study in a London borough" British Medical Journal 1996 volume 313, pp1189-1192 ${ }^{83}$ An alternative explanation for the lack of significant results between the two significant estimates (ie between 500 and 2500 metres) is that competition in those bands is suppressed by some form of coordination or local regulation (either by LMCs, or PCTs, or GP federations). In such cases it might be that the incentives to compete with immediate neighbours are of such significance that no agreement can be found to avoid competing. However the intensity (and thus the incentives) of competition is likely to fall as distances increase (patients are less willing to switch) and coordinated agreements become feasible. Finally at some distance (in this case $2500-3000$ metres) the GPs cease to impose coordinated agreements to not compete with one another on the basis that the gains from such an agreement are insignificant (most patients don't choose across such large distances and so are not tempted to switch).

${ }^{84}$ In contrast to paragraph [84](d) in which the number of patients with ACS conditions unsurprisingly increased the number of ACS referrals, we do not have any expectation as to the effect that the number of patients with ACS or other conditions will have on patient satisfaction levels at the practice.
}

\section{UNCLASSIFIED}


and reduce the capacity it has for treating other patients. Patients (with and without conditions) might then be more critical of the standard of care that they receive. This might explain the reduced satisfaction levels in practices with a larger proportion of people with: diabetes; Heart failure; mental Health problems; and hypertension.

Finally in the various surveyed patient characteristics we can see that:

a) Practices that had seen a higher proportion of respondents in the last six months were rated higher than those that had seen fewer. This might show that respondents who are familiar with their GPs give higher ratings.

b) Practices with a higher proportion of respondents that were retired or permanently disabled were rated higher than those with fewer retired or permanently disabled respondents. This might show that older respondents give higher ratings.

c) Practices with a higher proportion of respondents that considered themselves to be in good, very good or excellent health were rated higher than those with more respondents that considered themselves in fair or poor health. This might show that healthier respondents give some credit for this to their GP (or that those in poor health blame their GP).

\section{Discussion of the interpretation of the results}

In this section we discuss a number of factors that are important to consider when interpreting the results that we have obtained. Firstly we consider the possibility that some variables in the analysis are endogenously determined. Finally in the appendix we also consider an alternative interpretation of our results which we reject for the reasons described in the appendix.

\section{Endogeneity}

Interpreting the results can be complicated if, as is often the case, the analysis includes endogenous variables. A variable is endogenously determined if it is affected by changes in another variable within the analysis (ie it is not exogenous). The regression explains variations in the dependent variable (in this case quality) that are driven by the explanatory variables. Therefore any relationship between the explanatory variables, or feedback loops between the dependent and explanatory variables, may obscure the true effect that each explanatory variable has on the dependent variable. We have considered three potential endogeneities in this analysis:

a) That the quality of primary care provision at a GP practice may affect the number of rivals within a given distance band that the practice actually competes with, thus introducing measurement error to the competitive variables.

b) That the quality of primary care provision at a GP practice may affect the disease prevalence variables that describe the case mix that a GP practice faces.

\section{UNCLASSIFIED}


c) That the quality of primary care provision at a GP practice may affect the number of entrants into the local area that the GP practice faces.

This first potential endogeneity issue (a) relates to the measurement of the competitive variables. In particular, if higher quality increases demand but the practice is constrained in its ability to cater to that demand, then we do not measure competition accurately. For example a capacity constrained high quality provider will compete with fewer rivals located within a given distance band than our crude competitor count would suggest.

One way to think about this issue is that we effectively omit an unobserved variable that measures the ability of the practice to expand capacity. It is possible that this could create a negative bias on our estimate of the coefficient on the competitive variable..$^{85}$ As a result we might expect that we underestimate the relationship between competition and quality.

However, we are reassured that this is unlikely to affect our results for two reasons:

a) Firstly the smallest catchment area observed in Jenkins (1996) was more than 500 metres, while the average was more than 3000 metres. Thus our estimate of the coefficient on the 0 to 500 metres competitive variable will be unaffected by this bias. Similarly it is unlikely that the estimates on the competitive variables up to approximately 2000 metres will be affected by any bias.

b) Secondly catchment areas define which patients must be accepted; they do not define which patients cannot be accepted (nor do they describe where the actual patients of the practice are located). Any GP practice is therefore able to accept as many patients from outside its catchment area as it chooses to. Thus while the overlap of catchment areas may indicate more intense competition the lack of an overlap does not stop practices from competing.

The second issue (b) might arise if higher quality primary care services resulted in lower disease prevalence measurements at a given GP practice. However, the diseases that are included in this variable are essentially conditions that need to be managed by a primary care provider, rather than illnesses that are acquired due to poor quality primary care. This is reflected in the fact that a GP practice receives additional payment from the NHS for these patients. This payment recognises two important characteristics of these conditions: firstly that the additional care that they require is more costly than other patients, and secondly, that the GP is not responsible for the condition. Given this recognition of the GPs inability to influence the number of patients with a condition, we are confident that the form of endogeneity described above is not present.

The third issue (c) is common to many econometric models of this type. This is the concern that weak quality levels in an area will induce additional entry. For example this weakness might create

\footnotetext{
${ }^{85}$ To see this consider that the unobserved variable, the ability to expand capacity, is likely to be positively correlated with quality since better quality providers will find it easier to gain both permission from the PCT and the necessary funding to make expansion of capacity possible. However, the same variable is likely to be negatively correlated with the competitor count within a given distance band. This is because PCTs are reluctant to allow expansion where it will risk destabilising other GP practices (we have seen this in CCP cases). Since the product of these two correlations is negative this could suggest that the direction of the bias is likely to be negative.
}

UNCLASSIFIED 
an opportunity for profitable entry and hence encourage entry to be focused in areas with low quality providers. If that were the case then we may observe increased levels of competition where the quality of provision is weak. If the causality between the number of competitors and the quality of a GP practice were to run in both directions (that is, be endogenously determined) then our estimation would be biased and we would be unable to have confidence in our results.

However, given the characteristics of this particular market we know that entry into a primary care market is rare (we estimate 116 entries in 152 PCTs between 2004 and $2009 .{ }^{86}$ Moreover the entry that does occur is sponsored by the Department of Health and directed at a local level by PCTs towards areas that lack capacity, rather than to areas that have low quality providers. As a result there is little or no scope for entry to respond to the level of quality in a local market. We are therefore confident that the form of endogeneity described above is not present.

\section{Conclusions}

This paper contributes a number of key insights on the benefits of competition within the primary care market in England.

Firstly, increased GP competition ${ }^{87}$ is associated with a better quality of primary care (as indicated by GP practices making fewer ACS referrals). In this respect it is consistent with the finding that similar non-price competition in hospital markets is associated with better clinical outcomes ${ }^{88}$.

Secondly, whilst the ACS referrals are a useful indication of the broader clinical quality of a GP practice, they also represent avoidable referrals for expensive acute treatment that occur as a result of poor quality primary care. As such, this paper suggests that increased GP competition is associated with reduced taxpayer expenditure. ${ }^{89}$

Thirdly, the presence of additional rival GP practices is associated with patients being more satisfied with the efforts made by their GP practice. Improved levels of patient satisfaction reflect important aspects of the quality of service that the NHS provides to its patients, these include clinically important issues such as access to services, as well as aspects of the service which patients, as taxpayers, increasingly expect to receive from a modern NHS.

\footnotetext{
${ }^{86}$ This estimate is based on a comparison the GP practices present in the 2004/05 information centre dataset and those present in the 2008/09 dataset.

${ }^{87}$ As indicated by the presence of more rival GP practices located nearby

${ }^{88}$ See Cooper, Gibbons, Jones, and McGuire "Does Hospital Competition Save Lives? Evidence from the English NHS Patient Choice Reforms" 2010. See also Bloom, Propper, Seiler and Van Reenen "The Impact of Competition on Management Quality: Evidence from Public Hospitals" 2010. Gaynor, Moreno-Serra and Propper "Death by Market Power: Reform, Competition and Patient Outcomes in the National Health Service", 2010, NBER Working Paper No. 16164

${ }^{89}$ Our analysis indicates the degree of GP competition by reference to the number of competitors located in the area (ie the market structure). Given the importance of geographic location to patients (see Salisbury 1989 and Robertson, Dixon and Le Grand 2008) this is likely to be a good approximation of the degree of competition that a GP practice faces. However, our results may also suggest a wider conclusion, for example that quality levels might also increase if the intensity of competition between GP practices located in fixed locations were to increase. The intensity of competition depends on the emergence of a culture of competition as well as competitive structure. Developing the ability and incentives of patients and providers in order to allow competition to work effectively seems likely to be as important as developing and/or protecting the competitive structure of these markets, if not more so, in delivering the full benefits of competition to patients and taxpayers.
}

\section{UNCLASSIFIED}


Finally, in considering these results it should be recognised that these benefits are in evidence despite the presence of important restrictions on patient choice and competition. These restrictions include the designation of catchment areas, fixed payments to GPs and significant barriers to entry and expansion. This research would therefore suggest that removing these restrictions may improve the quality of care that GPs provide and reduce the cost of the NHS to taxpayers. 


\section{Bibliography}

- Audit Commission "More For less: Are Productivity and Efficiency Improving in the NHS?" Health Briefing, November 2009

- $\quad$ Beckert, $\mathrm{W}$ and Mazzarotto, $\mathrm{N}$ "Price-Concentration Analysis in Merger Cases with Differentiated Products" December 2006, http://www.competitioncommission.org.uk/our role/analysis/pc analysis merger cases.pdf

- Bekker, H, Bown, N, Bryant, L, and House A "The Lure of Patient Choice", October 2007, British Journal of General Practice, pp822-826

- Billinghurst, B and Whitfield, M "Why do Patients Change their General Practitioner? A Postal Questionnaire Study of Patients in Avon", British Journal of General Practice, August 1993

- Biorn, E and Godager G: "Does Quality Influence Choice of General Practitioner" Health Economics Research Programme at the University of Oslo, Working Paper 2008:3

- Bloom, N, Propper, C, Seiler, S and Van Reenen, J "The Impact of Competition on Management Quality: Evidence from Public Hospitals" 2010, NBER Working Papers 16032, National Bureau of Economic Research

- Boerma, W and Groenewegen, P "GP Home Visiting in 18 European Countries", European Journal of General Practice, 2001, Vol.7, No.4, pp132-137

- Borenstein, S "Airline Mergers, Airline Dominance and Market Power", 1990, American Economic Review, Vol.80, No.2, pp400-404

- Borenstein, S "Hubs and High Fares: Dominance and Market Power in the US Airline Industry", 1989, RAND, Journal of Economics, Vol.20, pp344-365

- Bresnahan, T and Reiss, P "Entry and Competition in Concentrated Markets", 1991, Journal of Political Economy, Vol.99, No.5, pp977-1009

- British Medical Association (General Practitioners Committee) "Reforming General Practice Boundaries" January 2010

- British Medical Association "How is General Practice Funded?" October 2008

- Brueckner, J, Dyer, N and Spiller, P "Fare Determination in Airline Hub-and-Spoke Networks", 1992, RAND Journal of Economics, Vol.23, No.3, pp309-333

- Carlsen, F, Grytten, J, Kjelvik J, and Skau, I "Better Primary Physician Services Lead to Fewer Hospital Admissions" March 2007, European Journal of Health Economics, Vol.8, No.1, pp1724

- Chalkley, M and Malcomson, J (1998) “Contracting for Health Services with Unmonitored Quality", 1998, Economics Journal, Vol.108, pp1093-1110 
- 'Competition and Regulation in Financial Services: Striking the Right Balance', Banking Review Team interim report, July 1999

- Competition Commission, "A Report on the Completed Acquisition of A3 Cinema Limited by Vue Entertainment Holdings (UK) Ltd", February 2006: http://www.competitioncommission.org.uk/inquiries/ref2005/vue/index.htm

- Competition Commission, "Supermarkets: A Report on the Supply of Groceries from Multiple Stores in the United Kingdom" October 2000: http://www.competitioncommission.org.uk/inquiries/completed/2000/index.htm\#supermarkets2

- Competition Commission, "The Supply of Groceries in the UK Market Investigation" April 2008: http://www.competition-commission.org.uk/inquiries/ref2006/grocery/index.htm

- Confederation of British Industry "Just What the Patient Ordered: Better GP Services" September 2007

- Cooper, Z, Gibbons, S, Jones, S, and McGuire, A "Does Hospital Competition Save Lives? Evidence from the English NHS Patient Choice Reforms" January 2010, LSE Health Working paper No: $16 / 2010$

- Cooper, Z, Gibbons, S, Jones, S, and McGuire, A “Does Hospital Competition Improve Efficiency? An Analysis of the Recent Market-Based Reforms to the English NHS" June 2010, Centre for Economic Performance, CEP Discussion Paper No.988

- Croxson, B, Perkins, A and Propper, C "Do Doctors Respond to Financial Incentives? UK Family Doctors and the GP Fundholder Scheme" Journal of Public Economics, February 2001, Vol.79, No.2, pp375-389

- Culyer, A and Newhouse, J, eds, "Handbook of Health Economics: Volume 1B" 2000 NorthHolland

- Cyrnak, A and Hannan, T "Is the Cluster Still Valid in Defining Banking Markets? Evidence from a New Data Source", 1999, Antitrust Bulletin, Vol.44, No.2, pp313-332

- Davis, P "Spatial Competition in Retail Markets: Movie Theatres", 2006, RAND Journal of Economics, Vol. 37, No. 4 pp964-982

- Davis, P "The Effect of Local Competition on Admission Prices in the US Motion Picture Exhibition Market", 2005, Journal of Law and Economics, Vol.48, No.2, pp677-708

- De Maeseneer, J, De Prins, L, Heyerick, J “Home Visits in Belgium: A Multivariate Analysis", European Journal of General Practice, 1999, Vol.5, No.1, pp11-14

- Deloitte "Report to NHS Employers: Adjusting the General Medical Services Allocation Formula for the Unavoidable Effects of Geographically-Dispersed Populations on Practice Sizes and Locations" March 2006

- Department of Health "Equality Impact Assessment: Initial Scoping Assessment and Action Plan for a National Consultation on Opening Up Choice of GP Practice" March 2010 
- Department of Health "Impact Assessment of Opening Up Choice of GP Practice" March 2010

- Department of Health "NHS Plan: A Plan for Investment, a Plan for Reform" July 2000, p11

- Department of Health "Our Health Our care Our Say: A New Direction for Community Services", January 2006

- Department of Health "Your Choice of GP Practice: A Consultation on How to Enable People to Register with the GP Practice of their Choice" March 2010 http://www.gpchoice.dh.gov.uk/wp-content/themes/gp-boundaries/documents/YourChoice-of-GP.pdf

- Department of Health "Your GP, Your Choice, Your Say: A Consultation on How to Enable People to Register with the GP practice of their Choice" March 2010

- Dixon, A, Le Grand, J, Robertson, R "Patient Choice in General Practice: The Implications of Patient Satisfaction Surveys" Journal of Health Services Research and Policy, Vol.3, No.2

- Dixon, P, Gravelle, H, Carr-Hill, R and Posnett, J "Patient Movements and Patient Choice" Report to the NHS Executive, University of York, York Health Economics Consortium, 1997

- Ellins, J, Ham, C and Parker, $\mathrm{H}$ "Choice and Competition in Primary Care: Much Ado about Nothing?" November 2008, Health Services Management Centre Policy Paper 2, University of Birmingham

- Elliott, B, Hole, A, Goudie, R, Gravelle, H, Ma, A, Morris, S, Sibbald, B, Skatun, D, and Sutton, $M$ “Determinants of General Practitioners' Wages in England" May 2009, Centre for Health Economics Research Paper 36, University of York

- Evans, W and Kessides, I "Living by the Golden Rule: Multimarket Contact in the US Airline Industry", 1994, Quarterly Journal of Economics, Vol.109, pp341-366

- Frontier Economics, "The Relationship Between Quality and Local Concentration: A Report Prepared for the Office of Fair Trading Pharmacy Investigation", March 2003: http://www.oft.gov.uk/shared oft/reports/comp policy/oft609annexem.pdf

- Gaynor, M “Competition and Quality in Hospital Markets: What do we know? What don't we know?" 2004, Economie Publique, Vol.15, pp3-40

- Gaynor, M, Moreno-Serra, R and Propper, C "Death by Market Power: Reform, Competition and Patient Outcomes in the National Health Service", July 2010, NBER Working Paper No. 16164: http://papers.nber.org/papers/w16164

- Gravelle, H, Morris, S, and Sutton, M “Are General Practitioners Good For You? Endogenous Supply and Health", October 2006, Centre for Health Economics Research Paper 20, University of York. 
- Gravelle, H, Morris, S, and Sutton, M “Doctor Behaviour Under a Pay for Performance Contract: Treating, Cheating and Case Funding?" February 2010, The Economic Journal, Vol.120, pp129-156

- Grey, D “A Dozen Facts about General Practice/Primary Care” July 2002 (http://www.gpcurriculum.co.uk/rcgp/12 facts.htm)

- Guilliford, M "Availability of Primary Care Doctors and Population Health in England: Is There an Association?" Journal of Public Health Medicine, 2002, Vol.24, No.4, pp252-254

- Hannan, T "The Functional Relationship Between Prices and Market Concentration: The Case of the Banking Industry", 1992, in Audretsch, D and Siegfried, J (eds.): Empirical Studies in Industrial Organization: Essays in Honor of Leonard W. Weiss, Norwell, MA: Kluwer

- Holland, P "Statistics and Causal Inference" December 1986, Journal of the American Statistical Association, Vol.81, No.396, pp945

- Hotelling, H “Stability in Competition" 1929, Economic Journal, Vol.39, pp41-57;

- Jenkins, C and Campbell, J "Catchment Areas in General Practice and their Relation to Size and Quality of Practice and Deprivation: A Descriptive Study in a London Borough" British Medical Journal, 1996 Vol.313, pp1189-1192

- Kaplan, S, Greenfield, S, and Ware, J "Impact of the Doctor-Patient Relationship on the Outcomes of Chronic Disease" in Stewart, M and Roter, D, eds, "Communicating With Medical Patients" Sage Publications, Newbury Park, CA

- Kim, E and Singal, V "Mergers and Market Power: Evidence from the Airline Industry", 1993, American Economics Review, Vol.83, No.3, pp549-569

- Kranton, R "Competition and the Incentive to Produce High Quality", 2003, Economica, Vol.70, pp385-404

- LECG "Quantitative Techniques in Competition Analysis" Prepared for the Office of Fair Trading, October 1999, Chapter 13, pp 87-93: http://www.oft.gov.uk/shared oft/reports/comp policy/oft266.pdf

- Lexecon, "The Relationship of Price and Concentration" in Competition Commission "International and Plantsbrook Group Plc: A Report on the Merger Situation" May 1995: http://www.competition-commission.org.uk/rep pub/reports/1995/fulltext/366a2.1.pdf

- Luras, $\mathrm{H}$ "General Practice: Four Essays on GP Behaviour and Individuals Preferences for GPs", Working paper 2004:1 University of Oslo Health Economics Research Programme

- Mankiw, G and Whinston, M "Free Entry and Social Inefficiency" Rand Journal of Economics, 1986, Vol.17 No.1, pp48-58

- Manuszak, M and Moul, C "Prices and Endogenous Market Structure in Office Supply Superstores" 2008, Journal of Industrial Economics, Vol. 56, Issue 1, pp94-112 
- Mazzeo, M "Competitive Outcomes in Product-Differentiated Oligopoly" The Review of Economics and Statistics, 2002, Vol.84, No.4, pp716-728

- Morisson, S and Winston, C "The Dynamics of Airline Pricing and Competition", 1990, American Economic Review, Vol.80, No.2, pp389-93

- Neumark, D and Sharpe, S "Market Structure and the Nature of Price Rigidity: Evidence from the Market for Consumer Deposits", 1992, Quarterly Journal of Economics, 107(2), 657-680

- NHS Connecting for Health "Connecting for Health Weekly Digest" 8 July 2009

- NHS Employers “NHS Employers' Evidence to the Pay Review Body on Doctors' and Dentists' Remuneration 2009/2010- General Medical Services" November 2008, p7

- OECD Working Party No. 3 on Co-operation and Enforcement, submission by the U.S. "Potential Pro-Competitive and Anti-Competitive Aspects of Trade/Business Associations" October 2007 http://www.ftc.gov/bc/international/docs/ustradeass.pdf

- OFT "Personal Current Accounts in the UK - an OFT market study" July 2008: http://www.oft.gov.uk/OFTwork/markets-work/completed/personal/

- OFT "The Control of Entry Regulations and Retail Pharmacy Services in the UK" March 2003: http://www.oft.gov.uk/OFTwork/markets-work/completed/pharmacies

- Ong, L, Haes, J, Hoos, A, and Lammes, F "Doctor-Patient communication: A Review of the literature", Social Science and Medicine, 1995, Vol.40, pp903

- Pinske, J, Slade, M and Brett, C "Spatial Competition: A Semi-Parametric Approach", 2002, Econometrica, 70, pp1111-1153

- Policy Exchange (Featherstone, $\mathrm{H}$ and Storey, C) "Which doctor? Putting Patients in Control of Primary Care" January 2010

- Roland, M, Elliott, M, Lyratzopoulos, G, Barbiere, J, Parker, R, Smith, P, Bower, P, and, Campbell, J "Reliability of Patient Responses in Pay for Performance Schemes: Analysis of National General Practitioner Patient Survey data in England"2009, British Medical Journal, Vol.339, pp3851

- Royal College of General Practitioners "The future direction of general practice: a roadmap" 2007

- Royal College of General Practitioners "The value of General Practice" Fact sheet, November 2006

- Salisbury, C “How do People Choose their Doctor?" September 1989, British Medical Journal, Vol.299, pp608-610

- Salop , S "Monopolistic Competition with Outside Goods" 1979, Bell Journal of Economics, Vol.10, pp141-156 
- Salop, S "Monopolistic Competition with Outside Goods", 1979, Bell journal of Economics, Vol.10, No.1, pp141-156

- Schaumans, C "Strategic Interaction Between General Practitioners and Specialists Implications for Gatekeeping", February 2008, http://ssrn.com/abstract=1107816

- Singal, V "Airline Mergers and Competition: An Integration of Stock and Product Price Effects", 1996, Journal of Business, Vol.69, No.2, pp233-268

- Social Market Founation (Corrigan, P) "Registering Choice: How Primary Care Should Change to Meet Patient Needs", 2005

- Social Market Foundation (Maclean, N) "Choice and Contestability in Primary Care", November 2004

- Stewart, M "Effective Physician Communication and Health Outcomes: A Review", Canadian Medical Association Journal, 1995, Vol.152, pp1423

- The King's Fund “An Anatomy of GP Referral Decisions", January 2007

- The King's Fund "Choice at the Point of Referral: Early Results of a Patient Survey", November 2009

- The King's Fund "General Practice in England: an Overview" Briefing, September 2009

- The King's Fund "Patient Choice: How Patients Choose and How Providers Respond", June 2010

- Waddams, $C$ and Chang, $T$ "Gain or Pain: Does Consumer Activity Reflect Utility Maximisation?" Centre for Competition Policy, University of East Anglia, Working Paper 0815 http://www.uea.ac.uk/polopoly fs/1.104668!ccp08-15.pdf

- Wartman, S, Morlock, F, Malitz et al. "Patient Understanding and Satisfaction as Predictors of Compliance" Medical Care, 1983, Vol. 21, pp886

- Wooldridge, J M “Introductory Economics" Third edition, Thomson South-Western, 2006 


\section{Appendix: The cooperation interpretation}

In this appendix we consider an alternative interpretation of our results. This is based on the suggestion by some health commentators that the finding of better quality in areas with larger numbers of competitors may reflect the benefit of cooperation between providers rather than competition.

\section{How to analyse cooperation}

Our competition hypothesis asks whether the presence of other practices that have the characteristics of competitors will encourage a given practice to increase the quality of its service. These characteristics include whether the practice is owned by a separate group of GP partners, and whether it is located near enough for patients to choose to be treated there. The results of the empirical analysis suggest that we should accept this hypothesis.

In contrast, to test a cooperation hypothesis we would need to identify a set of practices that we know, or expect, will cooperate with each other. The hypothesis would then be that increasing the number of co-operators (or the quality of the co-operators) will increase the quality of service at the practice.

Characteristics of co-operators might be that they are members of: the same local medical committee (LMC); the same local GP federation; the same practice based commissioning group (PBC); the same royal college; the same trade union, or the same PCT. Alternatively we might look at which conferences GPs attended, which magazines they subscribe to, or which medical school they were educated at.

The fixed number of local patients that need to select a GP means that GPs located near to one another may need to compete to attract patients. The key difference for a cooperation analysis is therefore that cooperation does not require proximity while competition does. In fact cooperation with the closest GP practices may be damaging for GP practices that do compete for patients. A cooperation analysis should focus on identifying hypothetical cooperative networks, not the number of practices within 500 or 1000 metres.

Interpreting the results

If cooperation networks were thought to be partly based on geography (eg the LMC membership), then we might expect to see a positive effect on quality from additional cooperating GPs in each distance band that falls within the cooperative group. However the area covered by an LMC, or a PBC cluster, or a local GP federation will all be many times larger than a 500 metre radius around a practice. Therefore the results that we obtain are inconsistent with a cooperation effect.

Lessons from QOF

As previously discussed, we might expect QOF scores to be improved by cooperating with other GPs. Importantly it is also possible that these other GPs will be willing to cooperate to improve one another's QOF scores. This is because QOF is a payment system in which an improvement in one 
GP's score does not penalise the GP that cooperated to help the GP improve his/her score. The same cannot be said for cooperation to improve patient satisfaction or clinical reputation of the practice since where this leads to one practice gaining patients it will penalise the practice that loses those patients (hence the practices are less likely to cooperate to improve one another's quality).

If there was a cooperation effect from the presence of other local GPs who cooperate to improve each other's QOF score, then we would expect to see positive coefficients on the competitive variables. This would show that the presence of additional GP practices improved a practice's QOF score. However, as shown below there is no significant effect. QOF scores do not vary according to the number of local 'co-operators'. If there is a cooperative effect on QOF scores these results suggest that it can only be across much larger distances (eg at a PCT level) and therefore should not be confused with the competition effect that we identify in this paper.

The results of the QOF regression are as follows:

Table 12. Regression results: QoF scores

\begin{tabular}{|c|c|c|c|}
\hline Dependent variable: QOF & Coefficient & t-statistic & Prob. $>t$ \\
\hline Comp0_500m & 0.0003 & 0.01 & 0.994 \\
\hline Comp500_1000m & 0.0321 & 1 & 0.319 \\
\hline Comp1000_1500m & -0.0297 & -1.15 & 0.252 \\
\hline Comp1500_2000m & 0.0272 & 1.16 & 0.245 \\
\hline Comp2000_2500m & 0.0068 & 0.33 & 0.743 \\
\hline Comp2500_3000m & 0.0138 & 0.67 & 0.503 \\
\hline Comp3000_3500m & 0.0167 & 0.91 & 0.364 \\
\hline Comp3500_4000m & -0.0063 & -0.35 & 0.725 \\
\hline Comp4000_4500m & -0.0150 & -0.92 & 0.359 \\
\hline Comp4500_5000m & 0.0002 & 0.01 & 0.992 \\
\hline No. GPs in the practice & 0.0823 & 1.74 & 0.082 \\
\hline List size & 0.0003 & 5.57 & 0 \\
\hline List size sq & 0.0000 & -6.09 & 0 \\
\hline Age weight: percent0_15 & -0.9557 & -0.32 & 0.747 \\
\hline Age weight: percent16_29 & 5.6587 & 2.49 & 0.013 \\
\hline Age weight: percent30_44 & 6.3498 & 2.44 & 0.015 \\
\hline Age weight: percent45_ret & 12.9048 & 3.18 & 0.001 \\
\hline MSOA: net change (per ‘000) & 0.0167 & 0.56 & 0.576 \\
\hline MSOA: birth rate (per '000) & -0.0052 & -0.22 & 0.824 \\
\hline MSOA: death rate (per ‘000) & 0.0089 & 0.37 & 0.71 \\
\hline Urban/Rural: cat 2 & 1.0000 & 0.72 & 0.47 \\
\hline Urban/Rural: cat 3 & 0.7613 & 0.5 & 0.615 \\
\hline Urban/Rural: cat 4 & 1.4060 & 0.66 & 0.511 \\
\hline Urban/Rural: cat 5 & 1.2592 & 0.99 & 0.32 \\
\hline Urban/Rural: cat 6 & 1.0265 & 0.8 & 0.421 \\
\hline
\end{tabular}

\section{UNCLASSIFIED}




\begin{tabular}{|c|c|c|c|}
\hline Urban/Rural: cat 7 & 1.6932 & 1.29 & 0.195 \\
\hline Urban/Rural: cat 8 & 2.1935 & 1.44 & 0.149 \\
\hline SHA2 (North West) & -0.1871 & -0.63 & 0.529 \\
\hline SHA3 (Yorkshire \& Humber) & -0.3062 & -0.97 & 0.334 \\
\hline SHA4 (East Midlands) & -0.2590 & -0.76 & 0.45 \\
\hline SHA5 (West Midlands) & -0.2129 & -0.65 & 0.517 \\
\hline SHA6 (East of England) & -0.4601 & -1.34 & 0.181 \\
\hline SHA7 (London) & -0.2040 & -0.53 & 0.595 \\
\hline SHA8 (South East) & -0.2161 & -0.61 & 0.543 \\
\hline SHA9 (South Central) & 0.1063 & 0.29 & 0.774 \\
\hline SHA10 (South West) & -0.0333 & -0.1 & 0.923 \\
\hline Prevalence: Coronary Heart Disease & -0.6670 & -6.48 & 0 \\
\hline Prevalence: Hypertension & -0.0220 & -0.76 & 0.447 \\
\hline Prevalence: Stroke or Transient Ischaemic Attacks & 0.1419 & 0.94 & 0.349 \\
\hline Prevalence: Chronic Obstructive Pulmonary Disease & -0.0361 & -0.35 & 0.723 \\
\hline Prevalence: Hypothyroidism & 0.4593 & 5.17 & 0 \\
\hline Prevalence: Cancer & 1.3352 & 7.76 & 0 \\
\hline Prevalence: Mental Health & -2.0433 & -16.85 & 0 \\
\hline Prevalence: Asthma & 0.2544 & 5.21 & 0 \\
\hline Prevalence: Heart Failure & -0.6134 & -1.98 & 0.047 \\
\hline Prevalence: Heart Failure due to LVD & 1.5730 & 4.28 & 0 \\
\hline Prevalence: Palliative Care & 2.8992 & 5.9 & 0 \\
\hline Prevalence: Dementia & -0.3528 & -3.68 & 0 \\
\hline Prevalence: Depression & 0.0565 & 4.01 & 0 \\
\hline Prevalence: Atrial Fibrillation & 1.1615 & 5.71 & 0 \\
\hline Prevalence: CKD & 0.1961 & 6.48 & 0 \\
\hline Prevalence: Diabetes & -0.0798 & -1.55 & 0.122 \\
\hline Prevalence: Epilepsy & -1.3416 & -5.06 & 0 \\
\hline Prevalence: Learning Disability & 1.0778 & 5.21 & 0 \\
\hline Prevalence: Obesity & 0.1820 & 10.05 & 0 \\
\hline constant & 83.6574 & 32.66 & 0 \\
\hline Number of obs & 8179 & & \\
\hline R-squared & 0.2076 & & \\
\hline
\end{tabular}

Notes: Statistically significant results are in bold. Working status, state of health, urban/rural, SHA and age weight variables each have a base variable which is excluded from the regression (eg SHA1) 